Conf $-9105172 \ldots-1$

UCRL-JC-1068C7-Rev. 1

Preprint

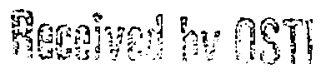

SEP 181991

\title{
Space Propulsion by Fusion in a Magnetic Dipole
}

E. Teller, A.J. Glass, T.K. Fowler,

A. Hasegawa, and J.F. Santarius

This paper was prepared for submittal to

\section{Fusion Technology}

and presentation at the First International A.D. Sakharov Conference on Physics, Moscow, USSR - May 27-31, 1991

July 15,1991

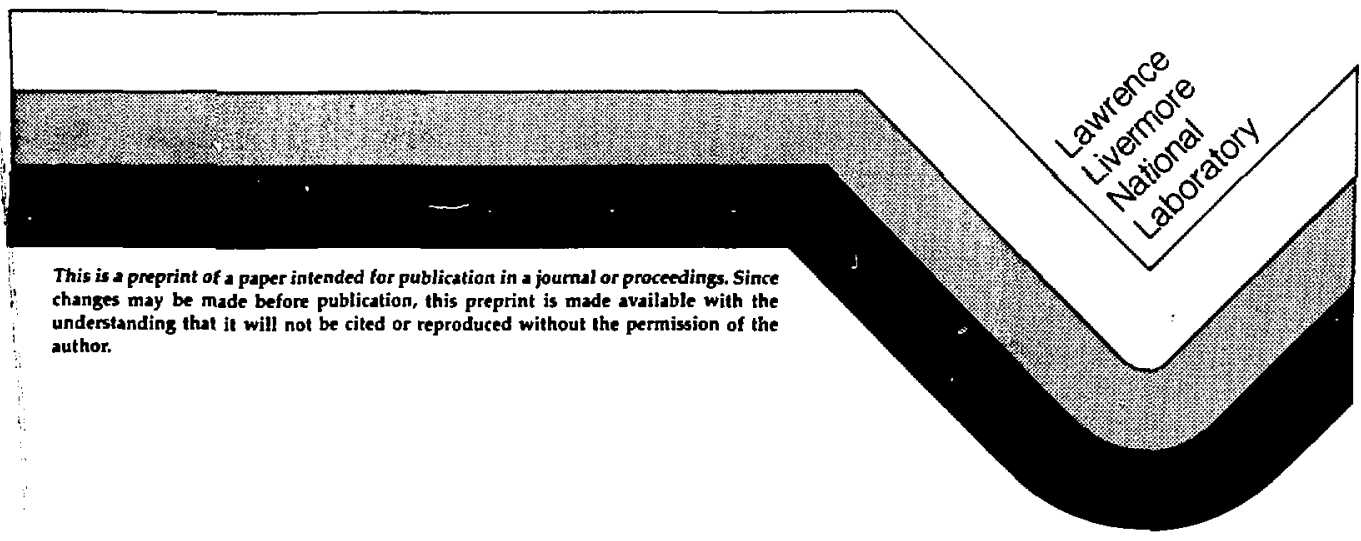




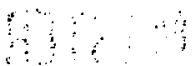

\section{DISCLAIMER}

This document was prepared as an account of work sponsored by an agency of the United States Covernment. Nether the United State Govemment no the Undversity of Californin nor any of their employees, makes any warranty, express or inplled, or anumes any legal liability or responsibility for the accuracy, completenes, or usefulnes of any informabion, apparatus, product, or process disciosed, or represents that its use would not infringe privately owned nights. Reference herein to any specific commerdal products, process, or service by trade name, trademark. manufacturer, or otherwise, does not necessarily constitute or imply its endorsement, recommendation, or favoring by the United States Covemment or the University of Callfornia. The views and opinions of authors expressed herein do not necesarily state or reflect those of the United States Govermment thereof, and shall not be used for advertising or product endorsement purposes 


\title{
SPACE PROPULSION BY FUSION IN A MAGNETIC DIPOLE
}

E. TELLER, A. J. GLASS, and T. K. FOWLER*

Lawrence Livermore National Laboratory

P.O. Box 808, L-640

Livermore, CA 94551

(415) $422-9866$

\author{
A. HASEGAWA \\ AT\&T Bell Laboratories \\ 600 Mountain Avenue, Rm. 1E351 \\ Murray Hill, NJ 07974 \\ J. F. SANTARIUS \\ University of Wisconsin - Madison \\ Fusion Technology Institute \\ 1500 Johnson Drive \\ Madison, WI 53706-1687
}

\begin{abstract}
Prepared for submission to Fusion Technology and presentation at the First International A.D. Sakharov Conference on Physics, Moscow, USSR May 27-31, 1991
\end{abstract}

*Consultant

Total number of pages: 36

Total number of figures: 14

Total number of tables: $\quad 2$ 


\section{ABSTRACT}

The unique advantages of fusion rocket propulsion systems for distant missions are explored using the magnetic dipole configuration as an example. The dipole is found to have features well suited to space applications. Parameters are presented for a system producing a specific power of $1 \mathrm{~kW} / \mathrm{kg}$, capable of interplanetary flights to Mars in 90 days and to Jupiter in a year, and of extra-solar-system flights to 1000 astronomical units (the Tau mission) in 20 years. This is about 10 times better specific power performance than nuclear electric fission systems. Possibilities to further increase the specific power toward $10 \mathrm{~kW} / \mathrm{kg}$ are discussed, as is an approach to implementing the concept through prooftesting on the moon.

\section{INTRODUCTION}

Nuclear fusion may offer unique advantages for space travel to the outer planets, far beyond the capability of chemical rockets (1). As we shall see below, despite the leading position of the tokamak in magnetic fusion research aimed at commercial electric power production, the special requirements of space propulsion favor other magnetic configurations less well studied in the laboratory. During the past 30 years, several nontokamak magnetic configurations have been analyzed and found to be attractive for space applications; a brief survey and further references are given in Ref. 1. Fur the present paper, we have chosen the magnetic dipole configuration supplemented by a simple solenoid. This choice was motivated by the fact that the dipole had not previously been examined in the context of space and by the belief that it could offer significant advantages over other configurations. These potential advantages include the simplicity of the dipole geometry ard the efficient use of the vast natural vacuum of space. The fringe magnetic field of the dipole should also provide partial biological shielding from solar-flare radiation. For the nuclear fusion fuel cycle, we consider rockets powered by a mixture of deuterium 
and helium-3 (D- ${ }^{3} \mathrm{He}$ ), as did many previous studies of magnetic fusion for space propulsion, for the reasons discussed in Seccion II.

The potential benefits of space propulsion by nuclear fusion will be briefly motivated here by a simple analysis. A more detailed discussion will be presented in Section IV.

Roughly, to accelerate a mass $M_{W}$ to a speed $v_{c}$ in a time $\tau$ requires a thrust power $P_{\mathrm{w}}$ given by

$$
P_{W}=\left(\frac{1}{2} M_{W} v_{c}^{2}\right) / \tau,
$$

from which we define the characteristic velocity $v_{c}$ by

$$
\mathrm{v}_{\mathrm{c}}=(2 \alpha \tau)^{1 / 2} \text {. }
$$

Here $\alpha=P_{\mathrm{w}} / M_{\mathrm{w}}$ is the specific power, defined in relation to the mass $M_{\mathrm{w}}$ of the propulsion system. The corresponding flight distance $I$, is roughly related to the flight time by

$$
\tau=K_{0} L / v_{\mathrm{c}} .
$$

where $\mathrm{K}_{0}$ is a constant of order unity. Combining Eqs. (1)-(3) gives, with appropriate units conversions,

$$
\tau(\text { years })=0.2 \frac{[L \text { (astronomical units })]^{2 / 3}}{[\alpha(\mathrm{kW} / \mathrm{kg})]^{1 / 3}} .
$$

Here we have chosen $K_{0}=3$ to provide a reasonable fit to example orbit calculations in the literature.

The payload delivered is the other key figure of merit besides the flight time in assessing rocket performance. The payload mass (including rocket structure) can be related to the initial rocket mass, including propellant, by the well-known "rocket equation":

$$
\frac{M_{L}}{M_{0}}=\exp \left(\frac{-u}{v_{\mathrm{ex}}}\right)
$$


where $u$ is the final rocket velocity. The rocket equation will serve to motivate the usefulness of fusion rocket capabilities, and a modified version, more appropriate to the optimized trajectories that fusion rockets would actually follow, will be discussed in Section IV. Optimum payload management typically corresponds to $v_{c}=\sqrt{2} v_{c x}$, with a final velocity near the characteristic velocity (2). Thus, to reach 1 A.U. in 1 year with a 0.1 payload fraction at a specific power of $1 \mathrm{~kW} / \mathrm{kg}$ requires an exhaust velocity on the order of $10^{5} \mathrm{~m} / \mathrm{s}$, or a specific impulse of about $10^{4} \mathrm{~s}$. These parameters are consistent with a dipole fusion rocket, but are beyond the capabilities of either nuclear fission thermal systems, in which reactors heat the propellant directly (high specific power, but low specific impulse), or nuclear fission electric systems, in which reactors supply electricity to ion accelerators (high specific impulse, but low specific power).

Figure 1 plots Eq. 4 for various high specific impulse systems and illustrates the potential of fusion propulsion. All values plotted in Fig. 1 correspond to $v_{\mathrm{ex}}<10^{6} \mathrm{~ms}^{-1}$, well within the capability of fusion rockets. In a fusion rocket $v_{\mathrm{ex}}$ can be readily adjusted up to $v_{\mathrm{ex}}=10^{7} \mathrm{~ms}^{-1}$ or a specific impulse of $10^{6} \mathrm{~s}$, corresponding to direct exhaust of the hot fuel as propellant, and even faster speeds could be achieved by selective exhaust of certain reaction products. However, as already noted, specific power rather than specific impulse is the primary constraint.

Specific powers in the range of $1 \mathrm{~kW} / \mathrm{kg}$, already an order of magnitude better than nuclear fission electric systems, appear quite feasible, and we shall discuss one such system, the dipole. As one can see from the figure, at a few $\mathrm{kW} / \mathrm{kg}$ specific power, interplanetary trips would require only months, and the Tau mission (thousand astronomical units) would require only 10-20 years.

The dipole reactor propulsion scheme is described in Section II, followed by thruster design in Section III, mission capabilities in Section IV, and steps to implement the concept in Section V. 


\section{FUSION PROPULSION SCHEME}

As already noted, though the tokamak is far ahead by virtue of superior performance in the laboratory, space applications appear to favor other configurations such as the dipole discussed here. The main reason is the need for simplicity and high specific power, always advantageous but absolutely necessary for space propulsion. Because the tokamak requires a strong toroidal field provided by massive coils interlinking the plasma, it will likely be difficult for tokamak designs to meet the specific power requirements outlined in Section I. Also, again because of the strong toroidal magnetic field, in the tokamak as normally configured there is no path of escape for the hot propellant plasma (as is required to produce thrust directly), and providing such an escape path would require a magnetic divenor far more massive and complex than the usual tokamak divertor that only serves to dump heat inside the machine.

Among the magnetic confinement systems that may in principle be better suited to space propulsion are the open systems, in which magnetic lines leaving the open ends of the machine provide a natural divertor. The best-studied open system is the tandem mirror. A detailed study of the tandem mirror for space applications yielded a specific power around $1 \mathrm{~kW} / \mathrm{kg}$, in the range of interest as discussed in Section I (1).

Here we have chosen as a different example the magnetic dipole configuration which, though less well studied than tokamaks and tandem mirrors, appears to offer advantages in terms of mass and simplicity. As in the tandem mirror study cited above, here we also consider the $\mathrm{D}$-îHe nuclear fusion process. We choose this process over the more conventional D-T fusion reaction because mainly charged particles are produced, the only neutrons being those from secondary $D$-D reactions and tritium produced by these reactions. Producing fewer neutrons requires less massive shielding and less massive radiators to dispose of waste heat (the only way to do so in space). The predominantly charged-particle energy output allows thrust to be produced directly by the plasma exhaust without recourse to inefficient conversion of heat to electricity to drive ion engines. Also, it 
is known that, through eons of solar-wind deposition, ${ }^{3} \mathrm{He}$ is abundantly available on the moon (3).

The dipole, being somewhat simpler than the tokamak or the tandem mirror, is expected to be less massive than either of these devices at the same power, and therefore the dipole may produce greater specific power. The overall configuration is shown in Fig. 2. Coil C (the dipole) carries a large current, of order $50 \mathrm{MA}$, and provides the strong field that confines the D- ${ }^{3} \mathrm{He}$ plasma in an annulus about the coil, as shown in Fig. 3. Coils $A, A^{\prime}$, and $B$ (the stabilizer) provide a weaker field that levitates the dipole against gravity or acceleration, at a stable position between the coils. The stabilizer also serves as the "divertor," whereby the closed magnetic lines of the dipole open up beyond the so-called separatrix flux surface containing an $\mathrm{X}$-point (field null). Heat diffusing onto the open lines provides the power to create thrust in the form of a magnetically accelerated ion beam that is converted to neutral atoms as it exits the rocket. This means of converting the energy of the magnetically confined plasma to a directed neutral beam is similar in principle to the neutral beam injectors now being used to heat tokamaks. The arrangement to accomplish this, sketched in Fig. 4, will be discussed in Section III.

\section{II.A. Dipole Properties}

Because of the limited experimental and computational database for the dipole configuration, we must rely in part on simplified theoretical models. We have cliosen to concentrate on assessing the feasibility of novel features of the concept and necessarily leave unresolved such important issues as aromalous plasma transport and plasma-wall interactions at the surface of the intemal $r$.Ig that require extensive experimental evaluation.

The dipole configuration has recently received renewed attention, as a candidate D-3He reactcr (4). As noted in the references, according to theory, supported by planetary and space observations, the dipole exhibits remarkable magnetohydrodynamic (MHD) stability up to local values of the pressure parameter $\beta$ exceeding unity (5). High beta is especially advantageous for D. ${ }^{3} \mathrm{He}$ operation. 
An important MHD design constraint concerns the well-known interchange instability whereby two tubes of equal magnetic flux but different volumes can exchange places if the kinetic energy of plasma confined by the outer flux tube is sufficiently much less than that on the inner tube. This situation does not occur if the plasma pressure decreases with radius no faster than $V-5 / 3$ where $V \sim r / B(r)$ is the volume of a flux tube at radius $r$ (measured in the plane of the dipole ring). This is just the condition that the combined effect of adiabatic expansion of the plasma moving outward to occupy a larger volume and compression of that moving inward to a smaller volume produces a net increase in kinetic energy. For our dipole reactor, for which, $B \sim r^{-3}$ at large distances, the marginally stable profile $p \sim V^{-5 / 3}$ corresponds to weakly decreasing $\beta \sim r-2 / 3$ in the plane of the ring. These results apply to isotropic pressure $(\gamma=5 / 3)$. In our case, the rarity of collisions on outer field lines may introduce anisotropy since too few collisions serves to deplete the density of mirror-trapper particles needed to fill out the isotropic velocity distribution at the outermost point on a field line where the field strength is weakest. However, since the missing trapped particles are destabilizing, we are surely safe in calculating the marginally stable pressure profile fur isotropic pressure. This is shown in Fig. 5, which plots the marginally stable profiles of $\beta$, the pressure (assumed isotropic), and the corresponding density and temperature profiles.

Since a gradient steeper than the marginal profile would produce strong turbulent transport, we would expect the plasma to relax to the marginal profile, and we will make this assumption hereafter. The important point for our design is that these marginally stable profiles require a finite density and pressure at the outer edge of the plasma. However, as we shall see, this requirement can generally be met by the propellant exhaust itself, which is not confined but is maintained by a steady throughput of propellant material heated by radial heat transport from the core. We shall retum to this point in Section III.

Heretofore the necessity for an internal ring in the dipole configuration has been considered a major drawback, not because of the need to levitate it (which has been done) 
but because of the impossibility of providing external cooling and electrical power to the ring during plasma operation. Here we shall adopt a radical view first suggested by John Dawson in the early 1980s (6). Namely, we shall consider a conceptual design in which heat input to the ring is balanced by radiative cooling from its surface, and the heat input itself provides, through one of several conversion options, ample internal electric power to refiggerate a shielded superconducting coil embedded in the ring. The only remaining need for direct access to the ring, for maintenance and recharging the coolant, should be sufficiently infrequent to be compatible with space flight. The ring design is discussed in Section II.C.

It is, of course, important to minimize heat transport to the ring surface. Since the deuterons in the $\mathrm{D}-3 \mathrm{He}$ fuel produce some neutrons, one must also pay attention to neutron heatin 3 and damage to the ring. In Section II.C, we shall conclude that, with modem insulating materials and a high-iemperature-emitting surface, it should be possible to design a ring of minor radius $a \simeq 2 \mathrm{~m}$ producing a magnetic field as high as $5 T$ at the surface of the ring and capable of radiating heat at the rate of about $1 \mathrm{MW} / \mathrm{m}^{2}$ (tungsten at $2700 \mathrm{~K}$ ).

The limitation on ring surface radiation in turn limits the fusion power density. Suppose the useful confinernent volume is an annulus of thickness $a_{\mathrm{p}}$ as shown in Fig. 3, where $a_{\mathrm{p}}$ is the pressure gradient length for the profiles in Fig. 5. Then, with a limit of $1 \mathrm{MW} / \mathrm{m}^{2}$ surface radiation, the fusion power density $p_{\text {fus }}$ averaged over the confinement volume could be ( $\left.2 \mathrm{MW} / \mathrm{m}^{2}\right) a_{\mathrm{p}}{ }^{-1}$ if half of the power is transported to the ring, or ( $\left.5 \mathrm{MW} / \mathrm{m}^{2}\right) a_{\mathrm{p}}{ }^{-1}$ if only $20 \%$ is transported inward, and so on:

$$
\text { pfus }=\left(\frac{100 \%}{\% \text { transported to ring }}\right) \times\left(\frac{1 \mathrm{MW}}{\mathrm{m}^{2}} \frac{1}{a_{\mathrm{p}}}\right)
$$

averaged over the annular volume

$$
V=2 \pi R \cdot 2 \pi a \cdot a_{\mathrm{p}} .
$$


Here $R$ and $a$ are the major and minor radii of the dipole coil and approximately, $a_{\mathrm{p}} \simeq a$. Equation (6) is compatible with local $\beta<1$ at $B=5$ T.

Heai transpor to the ring occurs by bremsstrahlung radiation, synchrotron radiation, neutrons, and direct plasma thermal transpor.

The largest source of ring heating is bremsstrahlung, which occurs at ä rate given by (Z)

$$
\begin{aligned}
& P_{\mathrm{B}}=5 \times 10^{-37} \sqrt{T_{\mathrm{c}}} n_{\mathrm{e}}^{2}\left[\mathrm{Z}_{\mathrm{cff}}\left(1+1.55 \times 10^{-3} T_{\mathrm{e}}+7.15 \times 10^{-6} T_{\mathrm{c}}{ }^{2}\right)\right. \\
& \left.+0.071\left(\Sigma Z_{\mathrm{i}}^{3} n \mathrm{j} / n_{\mathrm{e}}\right) T_{\mathrm{e}}^{-1 / 2}+0.00414 T_{\mathrm{e}}\right] \frac{\mathrm{W}}{\mathrm{m}^{3}},
\end{aligned}
$$

where $T_{\mathrm{e}}$ is in $\mathrm{keV}$ and $n$ is in $\mathrm{m}^{-3}$. Equation (8) inciudes e-c bremsstrahlung and relativistic corrections.

Neutron production, partly by D-D and partly by D-T reactions with tritium. produced by $D-D$, is:

$$
P_{\mathrm{n}}=\frac{1}{2} n_{\mathrm{D}}^{2} \sigma V_{\mathrm{DD}} \rightarrow \mathrm{n} \times 2.45 \mathrm{MeV}+n_{\mathrm{D}} n_{\mathrm{T}} \sigma V_{\mathrm{DT}} \times 14.1 \mathrm{MeV}
$$

where the sitium density $n_{\mathrm{T}}$ is given by

$$
n_{\mathrm{T}}=\frac{1}{2} n_{\mathrm{D}}^{2} \sigma V_{\mathrm{DD}} \rightarrow \mathrm{T} \tau_{\mathrm{T}}\left(1+n_{\mathrm{D}} \sigma V_{\mathrm{DT}} \tau_{\mathrm{T}}\right)^{-1}
$$

Necessarily the tritium confinement time $\tau_{T}$, comparable to that of ${ }^{3} \mathrm{He}$, must exceed the energy confinement time $\tau_{E}$ if ignition is to be maintained. We shall assume $\tau_{T}$ is roughly $3 \tau_{\mathrm{E} .}$ Specifically, we take

$$
\tau_{\mathrm{E}}=3 \frac{n_{\mathrm{e}}+n_{\mathrm{D}}+n_{\mathrm{He}}}{n_{\mathrm{D}} n_{\mathrm{He}}} \frac{\frac{3}{2} T}{\sigma V_{\mathrm{DHe}} E_{\mathrm{DHe}}} .
$$

Neutron heating, though smaller than bremsstrahlung, is especially important because neutrons penetrating to the core of the ring heat the superconductor.

We shall neglect synchrotron radiation to the ring. Synchrotron radiation should be weak at high beta, and in any case, with a resistivity about 10 times copper, the tungsten 
surface of the ring is a fairly good reflecior of synchrotron radiation. The calculation of synchrotron radiation, discussed at length in Ref. 6, is complicated because of internal absorption in the plasma and varying emission rates at different beta values within the plasma. We estimate a net rate at a few percent of the single-particle emission at full field. If the actual rate is higher, a properly shaped reflector, as shown in Fig. 2 , should greatly enhance plasma self-absorption and reduce the net emission to acceptable levelc.

Concerning direct plasma transport, $\because \mathrm{e}$ shall assume that inward heat d:ffusion, in the direction of a steeply increasing magnetic field, is given by the ion classical heat conduction, $\chi_{\mathrm{i}}$. The $\chi_{0}$ for transport outward is likely to be anomalous iut is not well known for dipoles at the high temperatures of interest. Here we shall simply derive what the value of $\chi_{0}$ must be for ignition and compare the required value with various conjectures. Our parameters allow $\chi_{0} \gg \chi_{i}$, but nonetheless heat confinement must be quite good to achieve D-3 ${ }^{3}$ He ignition in a device of reasonable size.

If indeed $\chi_{0} \gg \chi_{i}$, there would be much less transport toward the ring. Also, the peak in temperature (and density) occurs near the ring where the magretic field is maximum. To model this effect, we consider a slab of thickness $a_{\mathrm{p}}$ with $T=0$ at the edges. Let $T$ peak at a distance $x$ from one edge (toward the ring). Since fusion energy is produced on boih sides of the feak at about the same power density, in steady-state the energy confinement time must be about the same in the interval $x$, where $\chi=\chi_{i}$, and the interval $a_{\mathrm{p}}-x$, where $\chi=\chi_{0}$,

$$
\frac{x^{2}}{\chi_{i}}=\frac{\left(a_{p}-x\right)^{2}}{\chi_{0}}
$$

which yields for small $x$,

$$
x=\left(\frac{\chi_{\mathrm{i}}}{\chi_{\mathrm{o}}}\right)^{1 / 2} a_{\mathrm{p}}
$$


The fraction of power transported directly to the ring, being that produced in the interval $x$, is $x / a_{\mathrm{p}}$ and, since $x<<a_{\mathrm{p}}$, the magnetic field at the peak of temperature is approximately that at the surface of the ring. Only that portion of the fusion power in charged particles not radiated is transported. Thus

$$
P_{\text {Direct }}=\left(P_{\text {fus }}-P_{\mathrm{B}}-P_{\mathrm{n}}\right) \frac{x}{a_{\mathrm{p}}}
$$

where $P_{\text {fus }}$ is the total fusion power

$$
P_{\text {fus }}=P_{\mathrm{DHc}}+P_{\mathrm{DD}}+P_{\mathrm{DT}} \text {, }
$$

including both charged particle and neutron power, averaged over the volume. We find $x / a_{\mathrm{p}}=0.1$.

Results normalized to the total fusion power $P_{\text {fus }}$ are plotted in Figures $6-8$, as a function of the ratio of fuel densities $n_{\mathrm{Hd}} / n_{\mathrm{D}}$ at various plasma temperatures. Here

$$
P_{\text {Available for thrist }}=P_{\text {fus }}-P_{\mathrm{B}}-P_{\mathrm{n}}-P_{\text {Direct }} \text {, }
$$

and

$$
P_{\text {Loss to ring }}=\frac{1}{2}\left(P_{\mathrm{B}}+P_{\mathrm{n}}\right)+P_{\text {Direct }} .
$$

In Eq. (17), since the density and temperature peak near the ring surface, we assume that half of the radiation and neutrons impinge upon the ring.

These figures show that the fraction of the fusion power heating the ring decreases and the fraction at.ilable for thrust increases as the plasma temperature increases, within the range shown. At the higher temperature yielding the highest available thrust power, the optimum fuel mix to minimize ring heating is around $n_{\mathrm{He}}=0.6 n_{\mathrm{D}}$. However, the neutron heating of the core is reduced with greater enrichment of ${ }^{3} \mathrm{He}$.

\section{II.B. Parameturs}

Example parameters for the simple models discussed above are given in Table I for a rocket producing about 1250 to $1500 \mathrm{MW}$ available to produce thrust, that is, power flowing into the exhaust channel. The two cases shown are for two values of the current 
density. Neither case is fully optimized. For both cases we have chosen $T_{\mathrm{c}}=T_{\mathrm{i}}=70 \mathrm{keV}$ (plotted in Fig. 8) and $n_{\mathrm{He}}=n_{\mathrm{D}}$.

Among machine parameters, note that the magnetic field requirement is within present projections for large superconducting magnets employed in fusion research.

Concerning heat transfer properties, the quoted surface temperature of the ring corresponds to about $1 \mathrm{MW} / \mathrm{m}^{2}$ radiation from tungsten at a surface temperature of $2700 \mathrm{~K}$ emitting to free space. The radiation rate would be roughly the same even if a synchrotron reflector were necessary, as shown in Fig. 2. Since the reflector area would be some 10 times larger than the ring surface area, its temperature would be lower (around $1500 \mathrm{~K}$ ), and the radiation rate from the ring to the reflector ( $\propto T_{\text {ring }}^{4}-T_{\text {reflector }}^{4}$ ) would be $90 \%$ of that with no reflector. The emissivity is taken to be 0.3 in these calculations.

The power calculation in Table I approximately takes into account the nonuniformity in density and temperature with the conservative assumption that the pressure assumes the MHD-marginally stable profile $p \propto B^{2} / r$ (near the ring). Both the power calculation and the magnetic field calculations assumed cylindrical geometry and, therefore, toroidal effects that distort flux surfaces are neglected. An optimized design would allow a coil with noncircular minor cross section to match the ring surface and flux surface, and possibly a larger aspect ratio $R / a$. These refinements may increase the total volume and power but are not likely to greatly change the specific power.

Except for the power calculation, all quantities are calculated at the position near the ring where the temperature is maximum. The plasma transport coefficients are given by $\chi_{i}=r_{L_{i}}{ }^{2} v_{i i}$, with $r_{\mathrm{Li}}$ and $v_{\mathrm{ii}}$ being the ion Larmor radius and collision frequency, and $\chi_{0}=\left(a_{\mathrm{p}}^{2} / \tau_{\mathrm{E}}\right)$, with $\tau_{\mathrm{E}}$ chosen to achieve ignition. Note that the required $\chi_{0}$, corresponding to $\tau_{E} \sim 3 s$, is in the range of measured local anomalous transport coefficients in existing large tokamaks with ion temperatures of $10 \mathrm{keV}$ or so. Whether such values will persist at $70 \mathrm{keV}$ is not known, even in tokamaks. Moreover, some theoretical conjectures such as "gyro-Bohm" scaling $\left(\chi \propto T^{3 / 2} / B^{2}\right)$ suggest that anomalous transport is worse by an order 
of magnitude at the higher temperatures required for $\mathrm{D}-{ }^{3} \mathrm{He}$. On the other hand, the dipole may have points in its favor compared to tokamaks. First since in a tokamak the physical wall is rearer than that in a dipole, the gradient length $a_{\mathrm{p}}$ for the dipole should be somewhat larger than that for a tokamak of comparable major radius $R$. Secondly, the dipole might turn out to be less subject to the low-frequency turbulence causing anomalous transport in tokamaks (5). Only more experiments, or perhaps the large gyrokinetic transport codes now under development, can answer these questions.

Finally we note that the actual performance as measured by specific power is sensitive to the choice of shielding material and the conductor design. The results quoted in Table I assume a 1.35-m-thick shield as discussed in the next section. The conductor mass is significant, so that doubling the current density in Case B substantially reduces the ring mass and increases the specific power. Thruster parameters listed in the table are discussed in Section II.

\section{II.C. Magnet and Shield Design}

The key problems in designing the dipole magnet and shield shown in Fig. 2 are

- High-field solenoidal magnet design.

- Magnet shielding.

- Magnet and shield cooling.

- Plasma-surface interactions.

The magnet design assumes a current density up to $50 \mathrm{MA} / \mathrm{m}^{2}$ at a field at the conductor up to $20 \mathrm{~T}$, based on extrapolating from recent high-field, conceptual fusion reactor magnet designs (8). In order to estimate magnet mass, we have chosen $\mathrm{Nb}_{3} \mathrm{Sn}$ superconductor, $\mathrm{CuNb}$ stabilizer, and carbon-fiber-reinforced steel structure. Because the magnets must operate in microgravity, they are assumed to be cooled by forced flow of supercritical helium ( ${ }^{4} \mathrm{He}$ at $4.2 \mathrm{~K}$ and pressure greater than $\left.0.23 \mathrm{MPa}\right)$. The future availability of a high- $T_{\mathfrak{c}}$ superconductor of sufficiently high current density at the relevant magnetic fields would greatly facilitate the design by removing the need for inefficient 
refrigeration at liquid helium temperatures and allow a greatly reduced shield thickness. To avoid cuting magnetic flux lines by solid surfaces, the necessary refrigerators are placed within the radiation shield surrounding the magnet $(6)$. The refrigerators will be powered by electricity generated within the shield by thermoelectric converters, thermionic converters, or liquid metal heat engines. Figure 9 schematically illustrates the basic concepts involved.

Three interrelated and competing effects are involved in designing the magnet and shield: (1) The shield thickness must protect the magnet from neutron damage and must minimize the neutron heat load on the magnet, (2) the shield must provide sufficient room for the converters and refrigerators, and (3) the shield thickness should be minimized to increase the available fusion power. For this initial analysis, wie have not performed a detailed optimization of the design but have attempted to show the feasibility of the basic concepts.

The radial build for the magnet shield is shown in Fig. 10, for Case B, Table I, neglecting details of the generators and refrigerators. The shield axis is shifted outward by about $0.1 \mathrm{~m}$ from the magnet axis to account for the difference in neutron wall loading of about a factor of 5 between the inner and outer sides of the shield. The thin tungsten layer on the first wall is capable of radiating $\sim 1 \mathrm{MW} / \mathrm{m}^{2}$ at $2700 \mathrm{~K}$. This layer receives $\sim 0.9$ $\mathrm{MW} / \mathrm{m}^{2}$ of surface heat from particle transport and bremsstrahlung. Tungsten reflects synchrotron radiation well, but it is very dense, so a 0.3 -m-thick shield of carbon/carbonfiber $(\mathrm{C} / \mathrm{C})$ composite lies beneath the tungsten. The $\mathrm{C} / \mathrm{C}$ composite shield attenuates $90 \%$ of the incoming neutron flux. It is followed by $5 \mathrm{~cm}$ of insulation, through which $0.1 \%$ of the total surface heat flows to the next shield layer. Because the $\mathrm{C} / \mathrm{C}$ shield is thermally insulated, only a small $(\sim 3 \mathrm{~K})$ temperature difference exists across it, and the neutron heat is conducted to the tungsten layer on the surface. The temperature of the $\mathrm{C} / \mathrm{C}$ shield and tungsten layer rise to $\sim 2740 \mathrm{~K}$, so that the total radiated surface heat is $\sim 0.97 \mathrm{MW} / \mathrm{m}^{2}$. Borated water with $5 \%$ steel structure has been chosen for the remaining radiation shield, 
with thin layers ( $25 \mathrm{~mm}$ each) of $\mathrm{B}_{4} \mathrm{C}$ and $\mathrm{Pb}$ near the magnet to attenuate heating by a further $20 \%$, based on studies of shielding for terrestrial D- ${ }^{3} \mathrm{He}$ reactors $(2.10)$. The B$\mathrm{H}_{2} \mathrm{O}$ shield attenuates the neutron wall load by a factor of 10 for each $0.24 \mathrm{~m}$ of thickness, so the $0.9 \mathrm{~m}$ (average) shield thickness reduces the total heat load on this region by a factor of about 5600 . The net effect of this shield design is that the magnet, including the coil case, receives $\sim 467 \mathrm{~W}$ of power, which must be pumped eventually from a temperature of $4.2 \mathrm{~K}$ to the surface temperature of $\sim 2700 \mathrm{~K}$. The B- $\mathrm{H}_{2} \mathrm{O}$ shield is split into two sections: a 0.24-m section that absorbs about $2.95 \mathrm{MW}$ of neutron power and operates at $\sim 900 \mathrm{~K}$, and a $0.66-\mathrm{m}$ section that absorbs about $0.33 \mathrm{MW}$ of neutron power and operates at $\sim 300 \mathrm{~K}$. The $\mathrm{Pb} / \mathrm{B}_{4} \mathrm{C}$ final shield absorbs $117 \mathrm{~W}$ at $300 \mathrm{~K}$. The total heat that must be pumped from a given shield layer in-ludes heat pumped from lower layers and heat dissipated by the inefficiencies of real generators and heat pumps. The total mass of the present design is $-1180 \mathrm{Mg}$ (tonnes), although the inclusion of generators and refrigerators will increase this total somewhat. Further iteration o parameters would be necessary to optimize the design.

The options investigated here for generating power in situ are thermoelectric converters, thermionic converters, liquid metal heat engines, and synchrotron radiation conversion by rectennas (rectifying antennas). We have not attempted to address the question of the operation of these devices in the strong magnetic fields of the dipole configuraion. For conceptual thermoelectric converters, characteristic values are $0.43 \mathrm{MWe} / \mathrm{m}^{3}$ and efficiency $(\eta)$ of $34 \%$ at $1000 \mathrm{~K}(11)$. Characteristic values for conceprual thermionic converters are $1.3 \mathrm{MWe} / \mathrm{m}^{3}$ and $\eta=25 \%$ at $2900 \mathrm{~K}$ (12). For a liquid metal heat engine using MHD conversion, these values are extrapolated to be $2.5 \mathrm{MWe} / \mathrm{m}^{3}$ and $\eta=20 \%$ at $1000 \mathrm{~K}(13)$. Also, an interesting possibility exists for directly converting the synchrotron radiation power generated by the plasma to electricity using rectennas (14). Waveguides could carry some of the incident synchrotron radiation into high surface-to-volume ratio chambers, whose walls would be lined with rectennas tuned to appropriate frequencies. Estimates of the potential efficiency in the context of 
tokamak reactors were as high as $80 \%$ (14), and the volume required would be low. Thus, the four options discussed give us considerable confidence that the required power for magnet refrigeration and heat pumping of 10-20 MWe can be provided in the available space.

The heat flows and source terms for Case B, Table I, are shown in Fig. 9. We will analyze the heat pumps in tems of ideal systems and show that sufficient engineering design margin exists. The amount of work $W$ required for an ideal heat pump to move a quantity of heat $Q_{\mathrm{c}}$ from a "cold" temperature $T_{\mathrm{c}}$ to a "hot" temperature $T_{\mathrm{h}}$ is

$$
W=Q_{c}\left(\frac{T_{h}-T_{c}}{T_{c}}\right) .
$$

From $4.2 \mathrm{~K}$ to $300 \mathrm{~K}, 467 \mathrm{~W}$ must be pumped, so the work required of an ideal heat pump is $33 \mathrm{~kW}$. Likewise, $0.37 \mathrm{MW}(0.33 \mathrm{MW}$ neutrons, $0.03 \mathrm{MW}$ work, $0.01 \mathrm{MW}$ heat pumped) must be pumped from $300 \mathrm{~K}$ to $900 \mathrm{~K}$, with a required ideal work of $-0.74 \mathrm{MW}$; and $\sim 4 \mathrm{MW}$ must be pumped from $900 \mathrm{~K}$ to $2700 \mathrm{~K}$, requiring $\sim 8 \mathrm{MW}$. The total surface heat is $\sim 400 \mathrm{MW}$ and, if the energy conversion options discussed earlier lead to even $10 \%$ net conversion efficiency, $40 \mathrm{MWe}-\mathrm{a}$ factor of 4 margin-would be available to drive the heat pumps. For real refrigerators at low temperatures, data has been compiled by Strobridge (15). Refrigerators operating between $\sim 4 \mathrm{~K}$ and $300 \mathrm{~K}$, which could achieve $20 \%$ of the Camot efficiency in volumes less than $10 \mathrm{~m}^{3}$ at $500-\mathrm{W}$ cooling capacity, are well within reasonable extrapolations oí existing technoiogy. Át high temperatures (300$2700 \mathrm{~K}$ ), typical thermal efficiencies of $30-40 \%$ can be assumed.

An estimate of the necessary volumes can be obtained by examining the ideal gas cycle. Assume helium $\left({ }^{4} \mathrm{He}\right)$ is the working gas. Then $P V S / 3=$ constant and $P V=N k_{\mathrm{B}} T$, where the definitions are standard. We take a conservative value of $100 \mathrm{MPa}$ for the pressure that the walls of the heat pump can take at high temperature. We assume a $10-\mathrm{Hz}$ cycle rate for the piston, which can be driven efficiently by $\mathbf{I} \times \mathbf{B}$ forces in the strong 
dipole magnetic field. For example, one possible refrigerator configuration would be to place a chamber with volume $V_{1}$ in the shield at temperature $T_{1}$ and a chamber with volume $V_{2}$ in the shield at temperature $T_{2}$. Then for $T_{1}=3 T_{2}, V_{1}=V_{2} / 5.2$ and $P_{1}=15.6 P_{2}$. For $T_{1}=2700 \mathrm{~K}$ and $\delta T=50 \mathrm{~K}$, a pressure of $100 \mathrm{MPa}$ corresponds to a number density of

$2.6 \times 10^{27} \mathrm{~m}^{-3}$. The energy density contained in $\delta T$ is then $2.7 \mathrm{MJ} / \mathrm{m}^{3}$ in the $2700 \mathrm{~K}$ shield and $0.52 \mathrm{MJ} / \mathrm{m}^{3}$ in the $900 \mathrm{~K}$ shield. The heat pumped at $10 \mathrm{~Hz}$ is $5.2 \mathrm{MW} / \mathrm{m}^{3}$ in the $900 \mathrm{~K}$ shield for this ideal refrigerator. A similar analysis applies to the $900 \mathrm{~K} / 300 \mathrm{~K}$ case. Thus, even including non ideal effects, there should be sufficient volume available for the necessary refrigerators.

Therefore, although much detailed design and analysis remains for the magnet, shield, energy converters, and heat pumps, plausible solutions have been identified for each system.

An important problem area not yet considered is plasma surface interactions, especially sputtering of the ring surface by plasma directly transported to the ring.

Another area not covered here is plasma fueling and removal of helium and hydrogen ash.

\section{II.D. Potential Improvements}

One way to improve the specific power would be to employ a surface material of higher emissivity to obtain a higher fusion power density, pfus, given by Eq. (6). For example, materials such as carbon with 3 times the emissivity of tungsten (at the same temperature) would permit a surface radiation of $3 \mathrm{MW} / \mathrm{m}^{2}$ and a corresponding increase in Pfus- A small increase in field or higher beta could accommodate this increase in power density. The drawback is the poor conductivity of these high-emissivity materials, leading to poor reflection of synchrotren radiation. Or, at a higher value of beta, detailed calculations may show that synch otron radiation is tolerable.

Another possibility is a reduction in shielding, which contributes the bulk of the ring mass in Table I. As has already been mentioned in Section II.C, high-temperature 
superconductors could significantly reduce shielding requirements. Another possibility is other fuel cycles such as $\mathrm{p}^{-}{ }^{6} \mathrm{Li}$, discussed in Ref. 6 , which produce fewer neutrons than D. ${ }^{3} \mathrm{He}$. While other fuels tend to require still higher temperatures, and barely compete with bremsstrahlung losses, a more careful study is waranted. Dawson points out that $\mathrm{p}-{ }^{6} \mathrm{Li}$ produces an energetic ${ }^{3} \mathrm{He}$ that reacts with ${ }^{6} \mathrm{Li}$ to produce an energetic proton that in tum reacts with $6 \mathrm{~L} . \mathrm{i}$ tc increase the yield. Any means of reducing the shielding has the secondary benefit that the conductor can be placed nearer to the plasma so that the field at the conductor could be less. A lower field at the conductor reduces the requirement for structure, effectively increasing the average current density and reducing the mass. Reliance on low-density, strong fiber composites as structural material would further reduce the mass and increase the specific power.

\section{THRUSTER DESIGN}

\section{IfI.A. Matching Conditions}

An important issue of thruster design turns out to be the matching of the propellant throughput to the fusion power output at the X-point in Fig. 4.

There are two matching condirions. The first is given by,

$$
P=\frac{1}{2} \dot{M} v_{\mathrm{ex}}{ }^{2}=\left(\frac{1}{2} M_{\mathrm{i}} n 2 \pi R d\right)_{\mathrm{x}} v_{\mathrm{ex}}{ }^{3},
$$

where $n$ and $M_{\mathrm{i}}$ are the density and mass of propellant ions (hydrogen), $d$ is the width of the exhaust channel (see Fig. 4), $x$ denotes quantities at the $X$-point location, and again $v_{e x}$ is the desired propellant exhaust speed.

To understand the second matching condition, we must retum to the requirements for MHD stability in dipoles. As noted in Section II.A, stability requires that the pressure fall off no faster than the rate given by the marginal beta profile plotted in Fig. 5 $\left[\beta=\right.$ pressure $\left./\left(B^{2} / 2 \mu_{0}\right)\right]$. Since pressure $\simeq 2 n T$, this in turn prescribes a minimum density $n$ at each radius, depending on the temperature there. A typical marginally stable density 
profile is plotted in Fig. 5 for an assumed temperature profile and the correct marginal beta profile. The actual temperature profile wolld be determined by outward heat transpor with coefficient $\chi_{0}$ matched to a boundary condition at the $\mathrm{X}$-point given by

$$
T=T_{\mathrm{x}}=1 / 2 M_{\mathrm{i}} \mathrm{v}_{\mathrm{ex}}{ }^{2} \text {. }
$$

This assumes thermal equilibration between fuel ions and propellant. Then the system is MHD stable out to the X-point, if the edge density $n_{\mathrm{x}}$ maintained by propellant throughput exceeds the marginally stable value, namely,

$$
n_{\mathrm{x}} \geq\left(\beta_{\operatorname{marg}} \frac{B^{2}}{2 \mu_{0}} \frac{1}{2 T}\right)_{\mathrm{x}},
$$

where $n_{x}$ is the solution of Eq. (19) and $\beta_{\operatorname{marg}}$ at $x$ is given by the beta curve in Fig. 5. The exact criterion requires pmperly averaging $n_{\mathrm{x}}$ over the flux surface.

Simultaneous solution of Eqs. (19)-(21) gives a condition on the exhaust speed $\mathrm{v}_{\mathrm{ex}}$,

$$
v_{\mathrm{cx}}=\frac{2 P}{\left(B^{2} / 2 \mu_{0}\right)_{x}} \frac{1}{\left(2 \pi \mathrm{R} d \beta_{\mathrm{marg}}\right)_{x}} .
$$

This equation determines the size and field strength of the stabilizer coils, $A$ and $A^{\prime}$, in Fig. 2. To locate the $\mathrm{X}$-point at a particular radius $R_{\mathrm{x}}$, one chooses stabilizer coils of somewhat larger radius $R_{\mathrm{S}}$, producing a field equal to the dipole field at $R_{\mathrm{X}}$ given by the magnetic field curve in Fig. 5. Cancellation of the two equal fields creates the $\mathrm{X}$-point.

In principle, the designer would simply choose a convenient radius $R_{\mathrm{X}}$ that, by Eq. (22), allows a value of $v_{e x} \sim v_{c}$ (characteristic rocket speed) suitable for the most distant mission contemplated, consistent with Eqs. (1)-(5) discussed in Section I. However, a significant constraint is posed by the channel width $d$ determined by a competition of fuel particle diffusion across the field and fuel particle escape along magnetic lines that open to the ends beyond the $\mathrm{X}$-point. For a diffusion coefficient $D$, 


$$
d=\left(4 \cdot \frac{R_{\mathrm{x}}}{\mathrm{v}_{\mathrm{ex}}} \cdot D\right)^{1 / 2}
$$

where we take $R_{\mathrm{x}}$ as the approximate escape path length. Now, MHD stability does not necessarily prevail on the open lines in the exhaust channel, and indeed plasma in the exhaust channel (scrape-off layer) of tokamaks appears to diffuse at the Bohm rate, $D_{\mathrm{B}}=1 / 16(T / e B)$, characteristic of unstable systems. Taking $D=D_{\mathrm{B}}$ (with $T$ and $B$ at $x$ ) gives, by combining Eqs. (22) and (23),

$$
v_{\mathrm{cx}} \leq 0.1 \frac{\left(P / \beta_{\operatorname{marg} x}\right)^{2 / 3}}{(B R)_{x}}
$$

Taking parameters in Table $\mathrm{I}\left(P=1.2-1.5 \times 10^{9} \mathrm{~W}\right)$ and a convenient size $R_{\mathrm{X}}=$ $15 \mathrm{~m}$ (corresponding to $B_{\mathrm{X}}=0.5 \mathrm{~T}$ ), Eq. (24) gives $\mathrm{v}_{\mathrm{ex}}>10^{5} \mathrm{~ms}^{-1}$ at $R_{\mathrm{x}}=15 \mathrm{~m}$, consistent with interplanetary missions. With this model, more distant missions might require a specific design to stabilize the exhaust channel in order to reduce $d$ [for example, an exit field shaped like the gas-dynamic trap (16)]. Classical diffusion rates rather than the Bohn rate give very small channel widths, $d$, whereby Eq. (22) is not very restrictive even for the Tau mission (1000 astronomical units). Also, the limitations discussed here are less restrictive for a larger machine at higher power, since $v_{e x} \propto P$ by Eq. (22). However, by Fig. 1 there remains the ultimate limit on flight distance $L$ versus flight time $\tau$ imposed by the achievable specific power, $\alpha$.

Note that the fringe field of the dipole is sufficient to deflect $\mathrm{MeV}$ protons at distances 5-10R. Thus the magnetic field provides some degree of biological shielding from radiaion from solar flares in the near neighborhood of the propulsion system. This potential benefit must be traded against placing occupants far away from the thruster to reduce the mass of biological shielding from neutrons.

\section{B. Focusing Field}

Given $B_{\mathrm{x}}$ prescribed by the matching condition, levitation is accomplished by a combination of a uniform field created by coils $A$ and $A^{\prime}$ and a reverse current in coil $B$ to 
provide both the vertical $B_{\mathrm{x}}$ and a radial focusing component $B_{\mathrm{r}}$. For the inierplanetary mission discussed above, the acceleration is only $a \sim v_{\mathrm{ex}} / \tau \sim 10^{-3} \mathrm{~g}$, and the acceleration is even less for more distant missions. To levitate we require

$$
2 \pi R I B_{\mathrm{r}}=M a,
$$

where $B_{\mathrm{r}} \approx\left(\delta_{\mathrm{z}} / R_{\mathrm{x}}\right) B_{\mathrm{x}}$ for convenient coil currents, and $\delta_{\mathrm{z}}$ is the displacement about the midplane position. For our parameters $\left(l=50 \mathrm{MA}, B_{\mathrm{X}}=0.5 \mathrm{~T}\right.$, and $M \cong 1180$ to 1720 $\mathrm{Mg}$ ), the maximum vertical displacement linder acceleration would be $\delta_{\mathrm{y}} / R_{\mathrm{x}}<10^{-4}$ and the lateral focusing is similarly good.

\section{III.C. Propellant Injector and Neutralizer}

Since all magnetic lines close eventually, to generate thrust directly it is necessary somehow to detach propellant ions from magnetic lines. For parameters of interest here, ion orbits are small even in the fringe field of the stabilizer coils, and therefore ions would follow field lines. To detach them, we propose to install an annular neutralizer of controlled density $n_{0}$ as shown in Fig. 4 . It is well known from the design and construction of neutral-beam injectors that neutralization of hydrogen ions can be accomplished efficiently up to about $50 \mathrm{keV}$, corresponding to a specific power of $3 \times 10^{5} \mathrm{~s}(17)$. This would provide a sufficient specific impulse for the Tau mission. The condition, $n_{0} \sigma_{x} L_{N} \geq 1$, is easily met for a neutralizer length $L_{\mathrm{N}} \sim 1 \mathrm{~m}$ over a range of beam energies.

The arrangement, shown in Fig. 4, is similar to a hollow-anode arc, except that here the power is supplied by diffusion of beat from the burning plasma core. The gas is introduced into a propellant injector consisting of a hollow, annular gas box that intercepts the magnetic lines that form the exhaust channel adjacent to the separatrix flux surface. The annular ring is closed above (i.e., toward the ring; see Fig. 2) to prevent the escape of unionized gas and open below so that ions can escape. Electrons heated by energetic particles diffusing onto the open lines of the exhaust channel flow to the gas box, where they ionize and heat the gas. The strong magnetic gradient from the gas box near the dipole $(\sim 5 T)$ to the exit point $\left(B \sim B_{\mathrm{X}} \sim 0.5 \mathrm{~T}\right.$ for the example above) converts ion energy to mostly directed 
velocity $v_{c x, z}$ parallel to field lines, and the gradient in density as the flow accelerates from an average speed $1 / 4 v_{\mathrm{cx}}$ to $\mathrm{v}_{\mathrm{cx}, z} \sim \mathrm{v}_{\mathrm{cx}}$ creates an ambipolar potencial $\mathrm{e} \phi \approx T_{\mathrm{c}} \ln \left[\left(\mathrm{v}_{\mathrm{cx}, 2} / 1 / 4\right.\right.$ $v_{\mathrm{ex}}$ ] that further accelerates the ions by converting electron thermal energy to directed ion motion. In this way, most of the power available for thrust is in fact converted to directed ion velocity, and since charge exchange does not impart momentum, this directed ion velocity in turn becomes directed velocity of the energetic neutral atoms that create thrust as they exit the neutralizer.

Two features not shown in the figure reguire more detailed design. Their purpose is to recirculate the cold ions produced by charge exchange back into the neutralizer for reuse as a supply of neutral gas. This can be accomplished by a weak trim coil that diverts the exiting magnetic field lines out of the path of the exiting propellant, together with a re-entrant channel to retum gas back into the neutralizer. Cold ions created by charge exchange, thus diverted, would follow field lines into the return channel and be neutralized where field lines encounter the metal walls of the channel. By proper design, the holes through which gas could escape would be small, with width of order $d$ as shown in the figure. Consequently, the necessary neutralizer density $n_{0}$ can be maintained with much less mass flow than is required for the propellant. The condition is

$$
m_{\mathrm{i}} n_{0} 2 \pi R_{\mathrm{X}} d L_{\mathrm{N}} / t_{0}<\dot{M}=M_{0} / \tau
$$

where we must take $n_{0} \sigma_{x} L_{\mathrm{N}} \geq 1$ and the neutral lifetime is $t_{0} \approx L_{\mathrm{N}} / d u_{0}<10^{3} \mathrm{~ms}^{-1}$ for the cold neutralizer gas. For parameters of interest, this is satisfied merely if $d / L_{N} \ll 1$.

\section{III.D. Specific Power and Specific Impulse}

Based on the calculated power and payload mass in Table $\mathbf{I}$, the availabie specific power is about $1 \mathrm{~kW} / \mathrm{kg}$. However, the net specific power depends on the overall efficiency of converting the power available as heat inio neutral beam power exiting the rocket. The efficiency generally increases with channel temperature and hence also 
efficiency increases with the specific impulse, defined as $I_{\mathrm{sp}}=\mathrm{v}_{\mathrm{ex}} / \mathrm{g}$ where $\mathrm{g}$ is the gravitational acceleration of the surface of the Earth (higher termperature gives a higher exhaust speed $v_{\mathrm{cx}}$ ). On the other hand, specific missions may favor lower $I_{\mathrm{sp}}$ as discussed in the next section. The values quoted in Table I reflect these uncertainties, the lower value of specific power corresponding to an overall $50 \%$ conversion efficiency. The main sources of inefficiency are the ionization energy (typically $100 \mathrm{eV}$ per pair), which dominates at low temperature $\left(I_{\mathrm{sp}}=10^{4} \mathrm{~s}, 100 \mathrm{eV}\right)$; and the neutralizer efficiency, which for hydrogen exceeds $90 \%$ at $100 \mathrm{eV}$ but drops $1050 \%$ at $50 \mathrm{keV}\left(I_{\mathrm{sp}}=3 \times 10^{5} \mathrm{~s}\right)$ (Ref. 17 , Fig. 3). Other smaller inefficiencies, due to backflow into the gas box or residual electron thermal energy at the neutralizer, can be improved by optimizing the location of the propellant injector along the magnetic gradient between the dipole ring and the neutralizer location.

We note that, for specific impulses around $10^{5} \mathrm{~s}(10 \mathrm{keV})$ where the neutral beam approach is most efficient, the overall efficiency should be much greater than schemes employing conversion of heat to electricity (e.g., fission) because of the much greater efficiency of generating thrust power direculy in our scheme (more than $60 \%$ as shown in Fig. 7). Until the neutralizer efficiency drops off (above $50 \mathrm{keV}$ ), our direct heating power and the electric power of other schemes are converted to thrust with comparable efficiency. In either case, the greatest inefficiency is the ionization energy, whether electrons are heated by our scheme or accelerated electrostatically as in an ion source. The ion acceleration efficiencies, by our magnetic acceleration scheme or by electrostatic acceleration in ion propulsion engines, are comparable.

\section{MISSION CAPABILITIES}

Four main mission classes exist: surface-to-orbit, inner solar system, outer solar system, and extra-solar. The propulsion system requirements for each class differ greaty, but the different regimes can be usefully characterized by three parameters: specific power 
$\alpha$ introduced in Section I ( $\alpha \equiv$ thrust power/propulsion system mass), the specific impulse ( $I_{\mathrm{sp}} \equiv$ average exhaust velocity normalized by Earth's surface gravity $g$ ), and the thrust-toweight ratio (T/W $\equiv$ acceleration). The terminology developed for historic reasons but remains in common use.

This section will show that the D. ${ }^{3} \mathrm{He}$ dipole reactor discussed in this paper provides extersive capabilities within the solar system, its outer boundaries, and beyond. The specific power, specific impulse, and thrust-to-weight ratios available allow efficicnt propulsion to the inner planets and also enable active development of the outer solar system. The thrust-to-weigut ratios are not sufficient, however, for launching such systems irom Earth to orbit, which remains the domain of chemical rockets. For extra-solar missions, the thousand astronomical unit (Tau) mission appears feasible with a 20-year one-way trip time--a very atwactive value.

The importance of the specific power, as discussed in Section I, is that the maximum energy per unit mass which can be given to the propellant during mission time $\tau$ is $\alpha \tau$. Missions can be profitably analyzed in terms of a related parameter, the characteristic velocity $\left(v_{c} \equiv \sqrt{2 \alpha \tau}\right)$ given in Eq. (3). For missions with negligible propellant mass and perfectly tuned exhaust velocity, the characteristic velocity corresponds to the maximum energy imparted to the rocket (18). Maximizing the specific power is always advantageous.

The importance of the specific impulse arises in minimizing the energy expended in adding momentum to the rocket. In a stationary frame of reference, this energy is minimized by leaving the exhausted propellant with zero momentum, so that the rocket velocity $\mathrm{v}=\mathrm{v}_{\mathrm{ex}} \equiv I_{\mathrm{sp}} g$. As discussed in Section III, a $\mathrm{D}-{ }^{3} \mathrm{He}$ dipole fusion propulsion system provides a wide range of specific impulses. The ability to tune the exhaust velocity over at least a factor of 10 is critical to many missions. In this class of missions, payloads are typically a smell fraction of the initial rocket mass, and the energy needed for the trip is 
much larger than the minimum energy trajectory allows. For example, a 3-month trajectory to Mars is in this class.

The thrust-to-weight ratio, defined in terms of the weight of the given mass at Earth's surface, simply gives the rocket acceleration normalized to the Earth's surface gravitational acceleration, $g$. For constant power, high $v_{e x}$ means low thrust-to-weight, but there are situations, such as spiralling out of orbit, where higher thrust levels are desirable. Conversely, higher thrust is generated at low $v_{e x}$ (low exhaust temperature). When needed, the fusion dipole reactor could produce higher thrust-to-weight ratios by merely thermally heating the propellant by flowing it through a double-walled reflector, similar to that shown in Fig. 2. Most of the heat produced by the plasma would then be converted to the momentum of the hot propellant gas, with the specific impulse $\left(\propto v_{e x}\right)$ limited by materials considerations, as in chemical rockets.

In terms of the above parameters, the key advantages of $\mathrm{D}-{ }^{3} \mathrm{He}$ fusion reactors in general and the dipole in particular over the main alternatives, chemicals and nuclear fission, are that

- D- ${ }^{3} \mathrm{He}$ fusion can achieve much higher values of the specific impulse.

- The specific power can surpass fission by an order of magnitude for high specific impulse systems.

- The thrust-to-weight ratio and exhaust velocity can be tuned over a wide range. A comparison of fusion with chemical, nuclear thermal, and nuclear electric propulsion systems is given in Fig. 11, where we compare these systems in terms of specific impulse and thrust-to-weight. Chemical systems can generate the high thrust-toweight ratios necessary for launch from Earth to orbit. Nuclear thermal (fission) systems can double the specific impulse at similar thrust-to-weight ratios and are, perhaps, well suited for missions from low-Earh-orbit (LEO) to geosynchronous orbit (GEO) or the moon. Gas core thermal fission systems can reach higher temperatures and hence higher specific impulses. Nuclear electric (fission) systems can reach very high specific impulses, 
but they suffer from a low thrust-to-weight ratio because of a low specific power due to the need for thermal conversion of energy to electricity at relatively low efficiency and for a consequently large radiator mass. They are generally considered for cargo missions to the outer planets, because payload ratios can be large if long flight times are used. Figure 11 shows that fusion propulsion occupies a unique niche at high specific impulses and thrustto-weight ratios significantly greater than nuclear electric systems. In the remainder of this section we will discuss how these capabilities would enable efficient human and cargo transport throughout the solar system and beyond.

Finding the optimized low-thrust trajectory for a given mission remains an art rather than a science. Nevertheless, useful rules of thumb exist, and we can also draw on extensive calculations performed over the past 40 years (2). For example, as already noted, in terms of the characteristic velocity the choice $v_{e x}=v_{c} / \sqrt{2}$ approximately maximizes the payload ratio with constant exhaust velocity (2). For a 3-month mission with a propulsion system providing $1 \mathrm{~kW}_{\mathrm{thrus}} / \mathrm{kg}$, we find $\mathrm{v}_{\mathrm{C}}=125 \mathrm{~km} / \mathrm{s}$, corresponding to $l_{\mathrm{sp}} \simeq 12,500 \mathrm{~s}$ and an average thrust-to-weight ratio of $10^{-3}$. As shown in Fig. 11, these requirements match fusion well but, although the specific impulse is within the range of nuclear electric propulsion, the specific power appears beyond the capabilities of such systems. A more sophisticated analysis allowing variable thrust, illustrated in Fig. 12 (taken from Ref. 2), shows that for Mars missions the desirable range is $v_{\mathrm{ex}}=10^{2}-10^{3} \mathrm{~km}$ $\mathrm{s}^{-1}$ corresponding to $I_{\mathrm{sp}}=10^{4}-10^{5} \mathrm{~s}$.

By adding matter to the plasma exhaust stream, the specific impulse and thrust can be raded off and are approximately inversely proportional to each other. In general, this flexibility of fusion systems is most impontant for the shorter travel times desirable for transfort of humans. For cargo missions, where the main consideration is often having a large payload fraction and long travel times are allowed, there is litule performance difference batween constant and variable thrusc. 
The capabilities of a D. ${ }^{3} \mathrm{He}$ dipole propulsion system for optimized Mars missions are illustrated in Fig. 13, where the payload fraction is plotted versus round-trip time (2). For comparison, a chemical propulsion system would follow a minimum-energy (Hohmann) trajectory, with a one-way flight time of $\sim 9$ months and a payload fraction of 0.33. Table II compares the dipole's performance for missions to Mars, Jupiter, and Tau (thousand astronomical units), where we have now returned to a simpler methodology, using a constant exhaust velocity near the characteristic velocity, as explained in the following paragraph. Solar gravity $\left(6 \times 10^{-3} \mathrm{~m} / \mathrm{s}^{2}\right.$ at Earth orbit) does not significantly alter the present calculations. This analysis, although not fully optimized for fusion's flexibility in tailoring the thrust program, nevertheless indicates that a dipole fusion rocket greatly enhances capabilities in the inner solar system and enables very long-range missions.

For the present analysis, which follows Stuhlinger (2), we divide the rocket mass into payload mass $M_{\mathrm{L}}$, propulsion system mass $M_{\mathrm{w}}$, and propellant mass $M_{\mathrm{p}}=\dot{M} \pi$, where $\dot{M}$ is the propellant mass flow rate and $\tau$ is the total burn time for the mission. The propulsion system mass, including the fusion power source and all systems required to provide thrust, is conveniently parameterized by $\alpha=P_{\mathrm{w}} / M_{\mathrm{w}}$, where $P_{\mathrm{w}}$ is the total thrust power. We assume constant exhaust velocity along the rocket's direction of flight and constant propellant flow rate. The initial rocket mass is $M_{0}=M_{\mathrm{L}}+M_{\mathrm{w}}+M_{\mathrm{p}}$. The propellant exhaust velocity, $v_{\mathrm{ex}}$, and the rocket terminal velocity, $u$, are normalized to the characteristic velocity by $v^{*}=v_{\mathrm{ex}} / v_{\mathrm{c}}=v_{\mathrm{ex}} / \sqrt{2 \alpha \tau}$ and $u^{*}=u / v_{c}=u / \sqrt{2 \alpha \tau}$. The payload ratio can then be written

$$
\frac{M_{L}}{M_{0}}=e^{-\frac{u^{*}}{v^{*}}}-v^{* 2}\left(1-e^{-\frac{u^{*}}{v^{*}}}\right)
$$

This equation, plotted in Fig. 14, has a maximum payload ratio for an exhaust velocity near $v_{\mathrm{ex}}=v_{\mathrm{c}} / \sqrt{2}$, and it serves as a useful guide in initially estimating $\tau$. 
Thus, a D- ${ }^{3} \mathrm{He}$ dipole propulsion system permits efficient, large-scale missions throughout the solar system. In particular, D-3 ${ }^{3} \mathrm{He}$ dipole propulsion or other fusion propulsion systems with similar capabilities could support extensive research outposts on Mars, in the asteroid belt, or in orbit around the gas giant planets. Such outpostsanalogous to Antarctic research bases-would greatly increase solar system knowledge and would facilitate space development (1).

For all of the missions shown in Table II, the flight time could be further reduced if the specific power of the fusion dipole propulsion system could be increased even beyond the $1 \mathrm{~kW} / \mathrm{kg}$ best values found for our example designs in Table I. Several factors discussed in Section II.D could yield an improvement, perhaps to specific powers of $10 \mathrm{~kW} / \mathrm{kg}$.

Even so, it seems likely that the dipole fusion propulsion system will not exceed a specific power of $10 \mathrm{~kW} / \mathrm{kg}$. While this is 10 times our nominal case and 100 times better than nuclear electric systems, it still falls short of stellar missions within a human lifetime. At $10 \mathrm{~kW} / \mathrm{kg}$, the flight time even to the nearest star would require more than 100 years.

\section{IMPLEMENTATION}

We have shown that magnetic fusion offers an attractive solution to the problems of space propulsion, especially for missions to the outer planets and beyond. The reasons for this claim include the availability of a practically unlimited low-mass energy source (in contrast to chemical rockets), and the simplicity of construction involving essentially no moving parts, offering the possibility of long-term operation without human assistance. This contrasts with the requirements for fission and even more so with the requirements for inertial confinement fusion. The potential of fusion for space a:plications has been discussed extensively by Schulze (19).

For the contemplated missions for space travel, especially those of long duration, long-term operation with minimum maintenance is particularly important. The proposed 
dipole configuration is attractive for this application, because it involves no moving parts except those needed for fuel injection and internal refrigeration. Sample paramesers shown in Table I suggest that specific powers of $1 \mathrm{~kW} / \mathrm{kg}$, at a specific impulse of up to $3 \times 10^{5} \mathrm{~s}$ are possible. The relatively open structure of the dipole should simplify in-flight maintenance, which will rely on extensive use of robotics. Extensive experimentation is required, however, to assess the feasibility of long-term expeditions, and to minimize cost.

Although the dipole is fundamentally a simple structure, detailed consideration must be given to the design and construction of ancillary systems such as the intemal cooling system for the central conductor, the fuel system, the support coils, and the neutralizer. The ultimate performance of the system will be very sensitive to the efficiency of the neutralizer, and to the directionality of the ourput flow.

Maintenance and reliability are issues of paramount importance for deep space missions. For example, it may be necessary to develop the technology to segment the superconducting ring, to facilitate its repair in flight. Techniques for initiating the fusion burn in the dipole configuration and for restarting it in mid-mission must also be developed.

A further problem is the continued operation of automatic equipment for making measurements and for appropriate communication. This must be accomplished by apparaus that can survive operation in a high flux of energetic neutrons. The flux can be minimized by shielding or by distance, but a practical and optimal solution to this problem requires explicit proof.

Initial tests on the levitated dipole can be carried out in conventional laboratories. Recently a new dipole experiment has beeil built at Columbia University in order to investigate interchange instability and radial transport of plasma confined by a dipole magnetic field (20). The above experiment's vacuum chamber is $1.6 \mathrm{~m}$ in diameter, and the mechanically supported dipole can reach a field strength of 2 T. In this experiment, energeric electrons with energies up to $10 \mathrm{keV}$ are created with electron cyclotron 
resonance heating. Depending upon the density of the cooler background plasma, the energetic electrons will excite interchange instabilities. The onset of interchange instabilities will be used to determine marginal stability boundaries, and measurements of the radial diffusion of the energetic electrons will test models of collisionless particle transport in dipole magnetic fields.

Most of the physics research and technology development required to perfect fusion propulsion devices can be carried out in the laboratory. However, ultimately, a full-scale test of fusion propulsion will be required. Fusion propulsion devices are large and heavy. The dipole configurations described in Table I are comparable in size to a large fusion power plant, produce gigawatts of fusion power, and produce significant fluxes of energetic neutrons from the unavoidable D-D and D-T reactions. Conducting full-scale tests of such propulsion devices on earth will be challenging.

The first major step in the space program proposed by U.S. President George Bush is the establishment of a permanent lunar settlement. When such a lunar settlement is established, it will provide an ideal location for proof-testing the dipole fusion rocket. The lunar environment provides two of the immediate requirements for magnetic fusion: vacuum and low temperature. If high-temperature superconductors are available, the need for refrigeration is further reduced. (Note, however, that once the dipole starts operation, due to neutron heating, the central coil will require cooling, independent of the surrounding temperature.) An additional advantage of an established lunar settlement would be the availability of an infrastructure and people to conduct experiments and to modify equipment as required.

The low-gravity environment of the moon is an atractive place in which to construct and test the dipole rocket. Large components can be handled more easily on the lunar surface. Furthermore, as noted in Section I, the lunar soil is a potential source of the ${ }^{3}$ He fuel. Ultimately, when the prototype rocket is ready for flight testing, the lunar surface will be an attractive base from which to launch it. Since the moon's gravity is 
much less than that of Earh, the thrust needed to escape the moon is correspondingly less, and the stresses induced during launch would be reduced accordingly. Thus the strucnure of the rocket can be lighter and simpler if it is constructed for lunar launching.

It is likely that the first expedition outside the solar system, if ever accomplished, will be powered by magnetic fusion. Sakharov, as a pioneer of the release of thermonuclear energy in all its forms, deserves the distinction that the first vehicle passing Proxima Centauri should be named "Andrei Sakharov."

\section{ACKNOWLEDGEMENTS}

This work was performed in part under the auspices of the U.S. Department of Energy by the Lawrence Livermore National Laboratory under Contract W-7405-Eng-48, and in part by AT\&T Bell Laboratories and the University of Wisconsin.

The authors wish to thank Dr. B. Grant Logan for helpful discussions and for independently suggesting the idea of internal refrigeration of the coil. They also wish to thank Mr. Scott A. Carpenter, Lawrence Berkeley Laboratory, for carrying out the calculations and graphs shown in Figures 6-8. Thanks are also due to Drs. J. P. Blanchard, L. A. El-Guebaly, M. E. Mauel, and S. W. Van Sciver for useful discussions. 


\section{REFERENCES}

1. J. F. SANTARIUS, "Magnetic Fusion Energy and Space Development," Proceedings of 24th Intersociery Energy Conversion Engineering Conference, Vol. 5, (IEEE, New York, 1989) p. 2525; J. F. SANTARIUS, “Lunar ${ }^{3} \mathrm{He}$, Fusion Propulsion, and Space Development," to be published in Lunar Bases and Space Activities of the 21st Century-II (Lunar and Planetary Institute, Houston, 1991).

2. E. STUHLINGER, Ion Propulsion for Space Flight (McGraw-Hill, New York, 1964).

3. L. J. WITTENBERG, J. F. SANTARIUS, and G. L. KULCINSKI, Fusion Technol., 10, 167 (1986).

4. A. HASEGAWA, L. CHEN, and M. E. MAUEL, Nuclear Fusion, 30, 2405 (1990).

5. S. M. KRIMIGIS, T. P. ARMSTRONG, W. I. AXFORD, C. O. BOSTROM, C. Y. FAN, G. GLOECKLER, L. J. LANZEROTTI, E. P. KEATH, R. D. ZWICKL, J. F. CARBARY, and D. C. HAMILTON, Science, 206, 977, (1979); L. CHEN and A. HASEGAWA, J. Geophy. Res. 96, 1503 (1991).

6. J. M. DAWSON, "Advanced Fusion Reactors," in Fusion, Vol. 1, Part B, E. Teller, ed. (Academic Press, New York, 1981.) The idea of internal refrigeration, not mentioned in this article, was proposed by Dawson in the early 1980 s (unpublished, private communication).

7. J. R. MC NALLY, Nuclear Technology/Fusion, 2, 9 (1982).

8. J. SCHWARTZ et al., "24 Tesla Superconducting Toroidal Field Magnet Concept for a Commercial Tokamak Reactor," IEEE Transactions on Magnetics, 27, 2068 (1991).

9. L. A. EL-GUEBALY, "Shielding Design Options and Impact on Reactor Size and Cost for the Advanced Fuel Reactor Apollo," Proceedings of the IEEE Thirteenth 
Symposium on Fusion Engineering, IEEE Catalog No. 89CH2820-9 (IEEE, New York, 1990), p. 388.

10. L. A. EL-GUEBALY, private communication (1991).

11. M. L. UNDERWOOD, R. M. WILLIAMS, B. JEFFRIES-NAKAMURA, M. A. RYAN, and D. O'CONNER, "Performance Projections of Alternative AMTEC Systems and Devices," Proceedings of the Eighth Symposium on Space Nuclear Power Systems, Part One, (AIP, New York 1991) p. 472.

12. L. S. MASON, P. C. SCHMITZ, and D. R. GALLUP, "Lunar In-Core Thermionic Nuclear Reactor Power System Conceptual Design," Proceedings of the Eighth Symposium on Space Nuclear Power Systems, Part One (AIP, New York, 1991) p. 651.

13. G. W. SWIFT, A. MIGLIORI, T. HOFLER, and JOHN WHEATLEY, "Theory and Calculations for an Intrinsically Irreversible Acoustic Prime Mover Using Liquid Sodium as Primary Working Fluid," J. Acoust. Soc. Am., 78, 767 (1985).

14. B. G. LOGAN, Fusion Power Associates Annual Meeting, Washington, DC (1986).

15. T. R. STROBRIDGE, "Cryogenic Refrigerators-an Updated Survey," NBS Technical Note 655, U. S. Government Printing Office, Washington, D.C.

16. I. A. KOTEL'NIKOV, V. V. MIRNOV, V. P. NAGORNYJ, and D. D. RYUTOV, "New Results of Gas-Dynamic Trap Research," Proceedings of the Tenth International Conference on Plasma Physics and Controlled Nuclear Fusion Research, Vol. 2 (IAEA Nuclear Fusion Supplement, 1985) p.309.

17. W. B. KUNKEL, "Neutral Beam Injection," in Fusion, Vol. 1, Part B, E. Teller, ed., (Academic Press, New York, 1981).

18. J. H. IRVING, "Low Thrust Flight: Variable Exhaust Velocity in Gravitational Fields," Ch. 10 in Space Technology, H. S. Seifert, ed. (Wiley, New York, 1959). 
19. NORMAN R. SCHULZE, "Fusior Energy for Space Missions in the Twenty-First Century," NASA Draft Report, February 14, 1991.

20. M. E. MAUEL and A. HASEGAWA, "Measurement of Nonadiabatic and Chaotic Charged-Particle Motion in a Collisionless Laboratory Terrella," to be published in Physics of Space Plasmas (1990), SPI Conference Proceedings and Reprint Series, No. 10, T. Chang, G. B. Crew, and J. R. Jasperse, eds. (Scientific Publishers, Cambridge, MA, 1991). 
Table I. Example parameters.

Case A

Case B

Reactor

$R$

$6.6 \mathrm{~m}$

$6 \mathrm{~m}$

$a$

$2.2 \mathrm{~m}$

$2.0 \mathrm{~m}$

$B$ (conductor)

$14 \mathrm{~T}$

$18 \mathrm{~T}$

Current density

Ring surface temperature

\section{$25 \mathrm{MA} / \mathrm{m}^{2}$}

$48 \mathrm{MA} / \mathrm{m}^{2}$

$2700 \mathrm{~K}$

Fusion power

Power available for thrust

$2500 \mathrm{MW}$

$2700 \mathrm{~K}$

$2000 \mathrm{MW}$

$1500 \mathrm{MW}$

$1250 \mathrm{MW}$

Ring mass

$1720 \mathrm{Mg}$

$1180 \mathrm{Mg}$

Plasma

$T$ (peak)

$70 \mathrm{keV}$

$70 \mathrm{keV}$

$n_{\mathrm{c}}$ (peak)

$4 \times 10^{20} \mathrm{~m}^{-3}$

$4 \times 10^{20} \mathrm{~m}^{-3}$

$n_{\text {He/ }} n_{\mathrm{D}}$

$B$ (plasma)

1

1

$\beta$ (peak)

$4.7 \mathrm{~T}$

$5.0 \mathrm{~T}$

$x i$

0.7

0.7

$0.002 \mathrm{~m}^{2} \mathrm{~s}^{-1}$

$0.002 \mathrm{~m}^{2} \mathrm{~s}^{-1}$

$x_{0}$

$1.0 \mathrm{~m}^{2} \mathrm{~s}^{-1}$

$1.0 \mathrm{~m}^{2} \mathrm{~s}^{-1}$

$\chi / a_{\mathrm{p}}$

0.1

0.1

$P_{\mathrm{B}} / P_{\text {fus }}$

0.3

0.3

$P_{N} / P_{\text {fus }}$

0.03

0.03

Thruster

Specific power $\alpha$

Specific impulse

$0.4-0.8 \mathrm{~kW} / \mathrm{kg}$

$0.5-1.0 \mathrm{~kW} / \mathrm{kg}$

$10^{4} s-3 \times 10^{5} s$

$10^{4} s-3 \times 10^{5} s$ 
Table II. Dipole performance for various missions.

\begin{tabular}{l|l|l|l} 
& \multicolumn{1}{l}{ Mars } & Jupiter & Tau \\
\hline One-way flight time, $\tau$ (years) & 0.25 & 1 & 20 \\
Characteristic velocity (m/s) & $1.3 \times 10^{5}$ & $2.5 \times 10^{5}$ & $1.1 \times 10^{6}$ \\
Exhaust velocity (m/s) & $1.0 \times 10^{5}$ & $1.8 \times 10^{5}$ & $6.7 \times 10^{5}$ \\
Mass flow rate (kg/s) & 0.25 & 0.081 & 0.0055 \\
Thrust (N) & $2.5 \times 10^{4}$ & $1.4 \times 10^{4}$ & $3.7 \times 10^{3}$ \\
Initial mass $(\mathrm{kg})$ & $5.0 \times 10^{6}$ & $4.0 \times 10^{6}$ & $4.8 \times 10^{6}$ \\
Thrust system mass (kg) & $1.25 \times 10^{6}$ & $1.25 \times 10^{6}$ & $1.25 \times 10^{6}$ \\
Propellant mass (kg) & $2.0 \times 10^{6}$ & $2.6 \times 10^{6}$ & $3.5 \times 10^{6}$ \\
Payload mass (kg) & $1.8 \times 10^{6}$ & $2.3 \times 10^{5}$ & $5.4 \times 10^{4}$ \\
Payload ratio & 0.35 & 0.058 & 0.011 \\
Thrust power (MW) & 1250 & 1250 & 1250 \\
\hline . & & & \\
\hline
\end{tabular}




\section{FIGURE CAPTIONS}

Figure 1. Mission distance $L$ versus flight time $\tau$ for different ratios of thrust power to mass of propulsion system.

Figure 2. Dipole reactor propulsion scheme.

Figure 3. Expanded cross-sectional view of magnetic flux surfaces and plasma.

Figure 4. Detail of propellant feed and thruster.

Figure 5. Approximate profiles of magnetic field, beta, temperature (dashed line), density, and plasma pressure (adapted from Ref. 5).

Figure 6. Power loss to the ring, as a percentage of the total themonuclear power $P_{\text {fus }}$ for different tempcratures as a function of the fuel mix $n_{\mathrm{Hd}} / n_{\mathrm{D}}$. (Courtesy S. A. Carpenter).

Figure 7. Power available for thrust, as a percentage of the total thermonuclear power $P_{\text {fus }}$ for different temperatures as a function of the fuel mix $n_{\mathrm{He}} / n_{\mathrm{D}}$. (Courtesy S. A. Carpenter).

Figure 8. Various power losses to the ring, as a percentage of the total thermonuclear power $P_{\text {fus }}$ at $T=70 \mathrm{keV}$ as a function of the fuel mix $n_{\mathrm{Hd}} / n_{\mathrm{D}}$. (Courtesy S. A. Carpenter).

Figure 9. Ring design concept showing magnet, shield, and internal refrigeration scheme.

Figure 10. Radial build of magnet and shield, for Case B, Table I. First wall is at the top, axis at bottom. Masses are given for each layer at the right.

Figure 11. Comparison of D- ${ }^{3} \mathrm{He}$ fusion with chemical, nuclear thermal, and nuclear electric propulsion systems.

Figure 12. Exhaust velocity variation on a 3-month transfer trajectory to Mars (based on Stuhlinger, Ref. 3).

Figure 13. Earth-Mars payload fracrion versus round-rip time. 
Figure 14. Payload fraction $M_{\mathrm{V}} / M_{0}$ versus exhaust velocity $\mathrm{v}^{*}$ (normalized to the characteristic velocity $v_{c}$ ) for various values of the total velocity change $u^{*}$ (also normalized to $v_{c}$ ). 


\section{LIST OF TABLES}

I. Example parameters.

II. Dipole performance for various missions. 


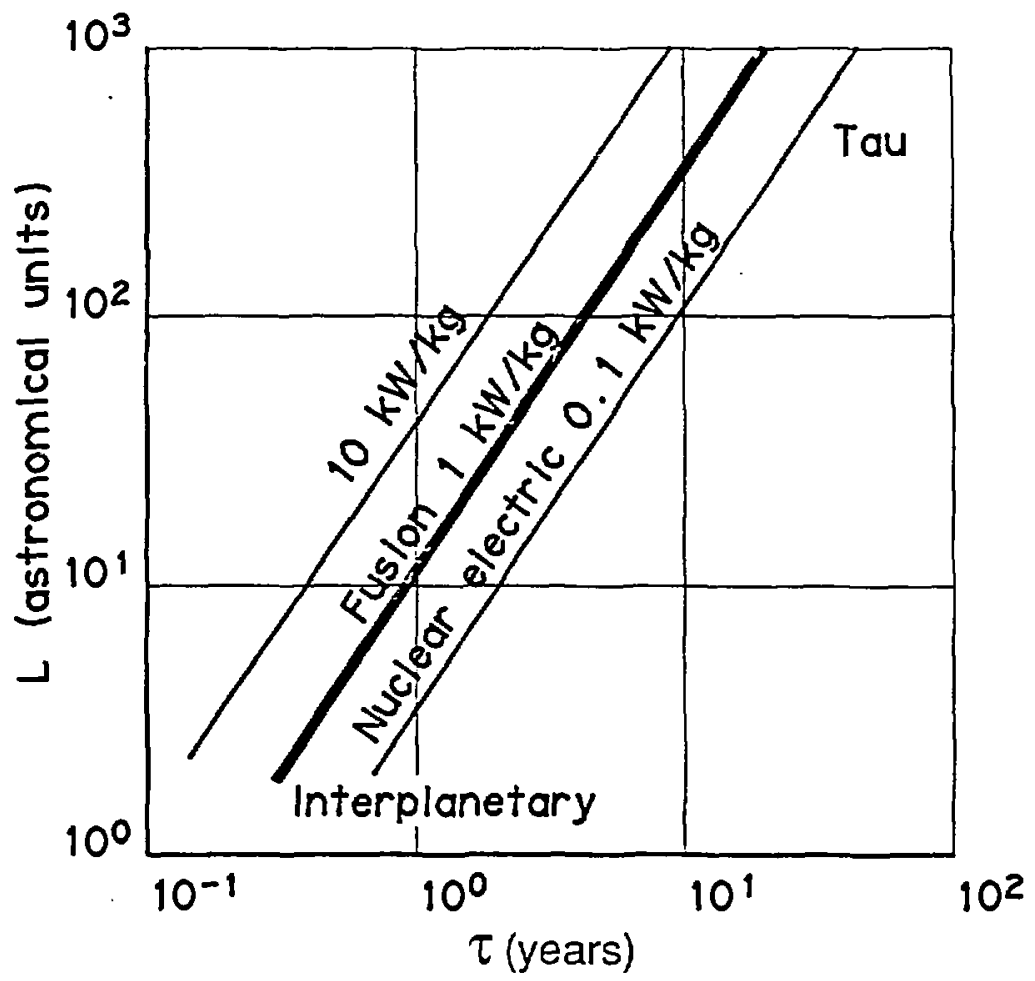

Figure 1. Vission distance $L$ versus flight time $\tau$ for different ratios of thrust power to mass of propulsion system. 


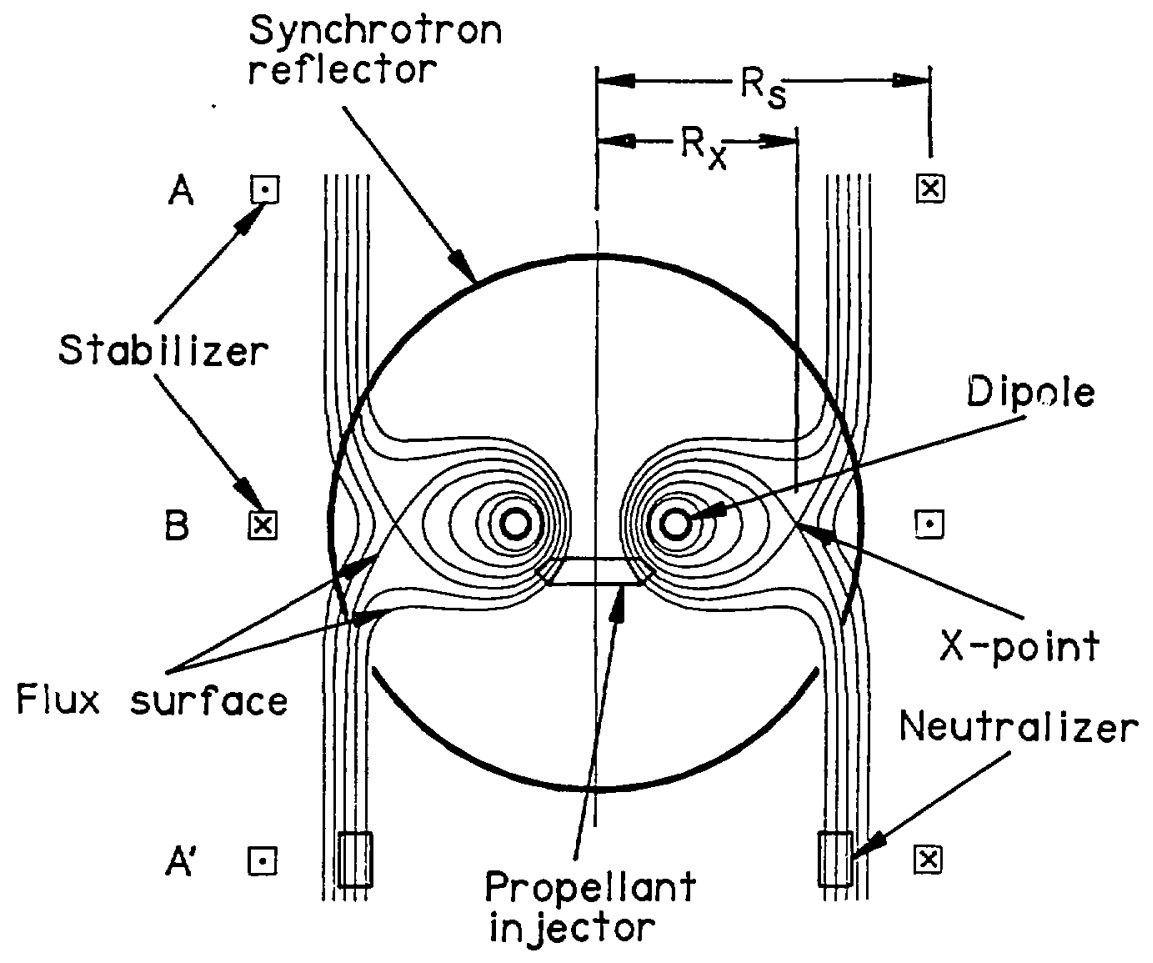

Figure 2. Dipole reactor propulsion scheme. 


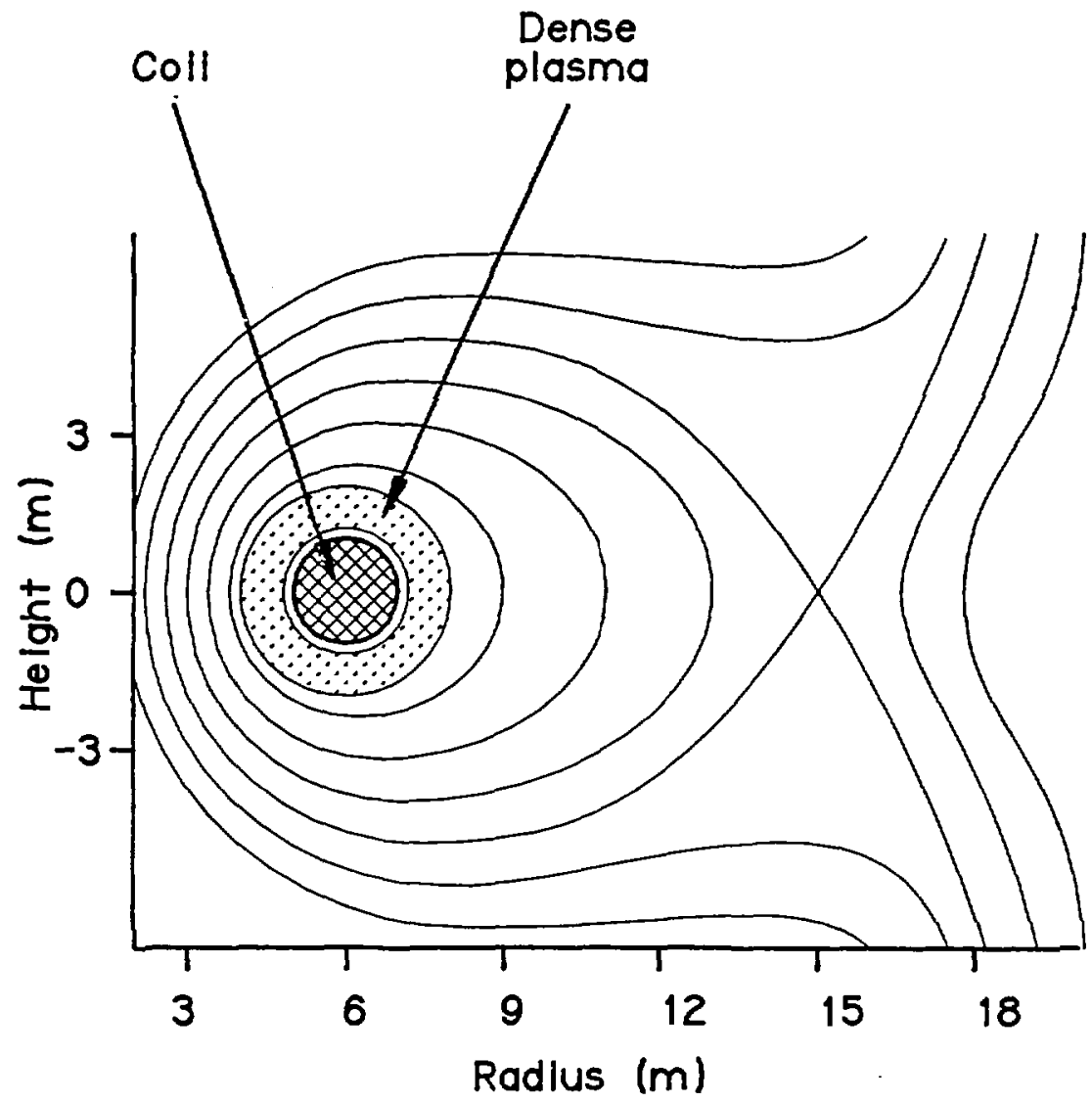

Figure 3. Expanded cross-sectional view of magnetic flux surfaces and plasma. 


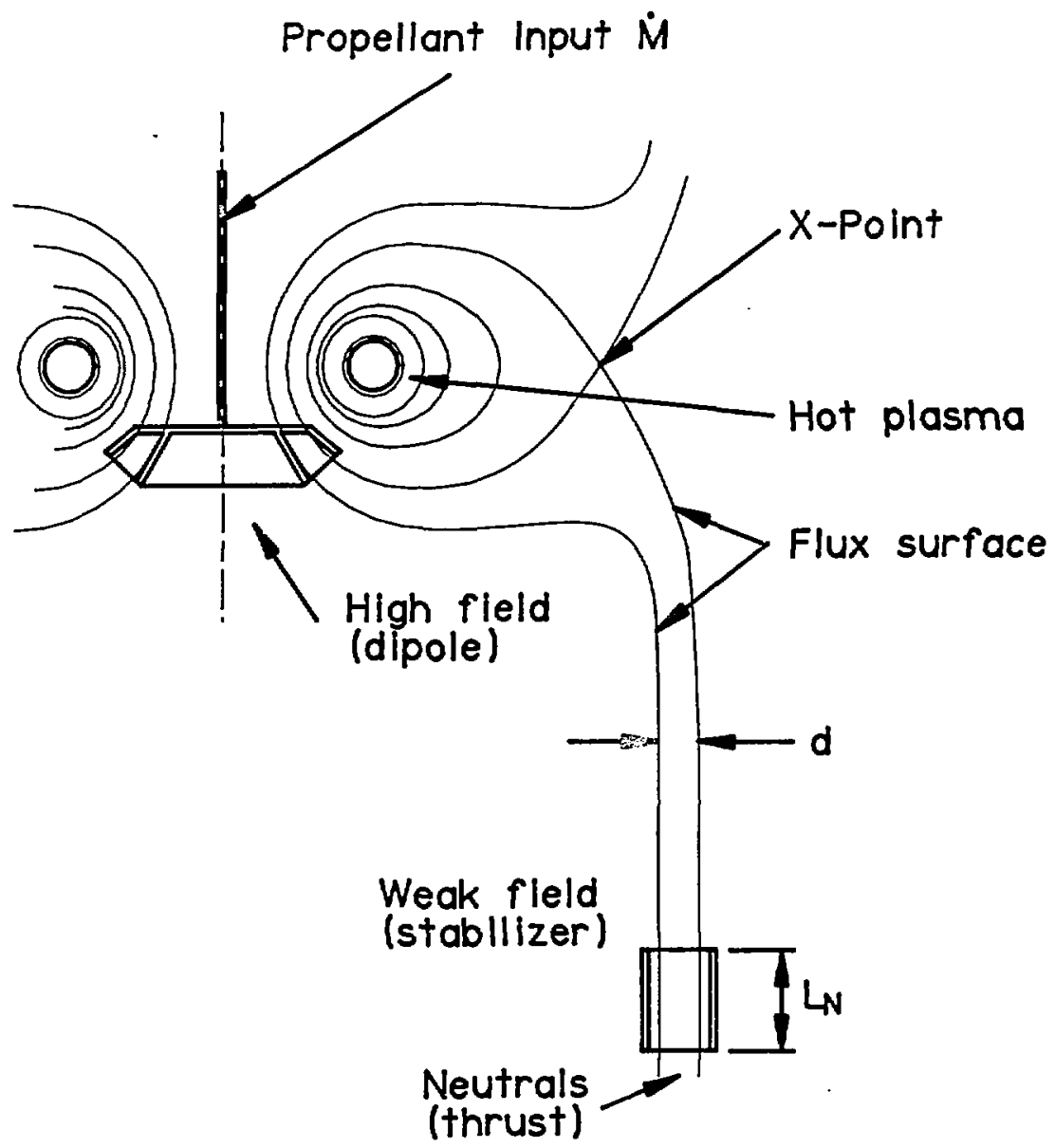

Figure 4. Detail of propellant feed and thruster. 


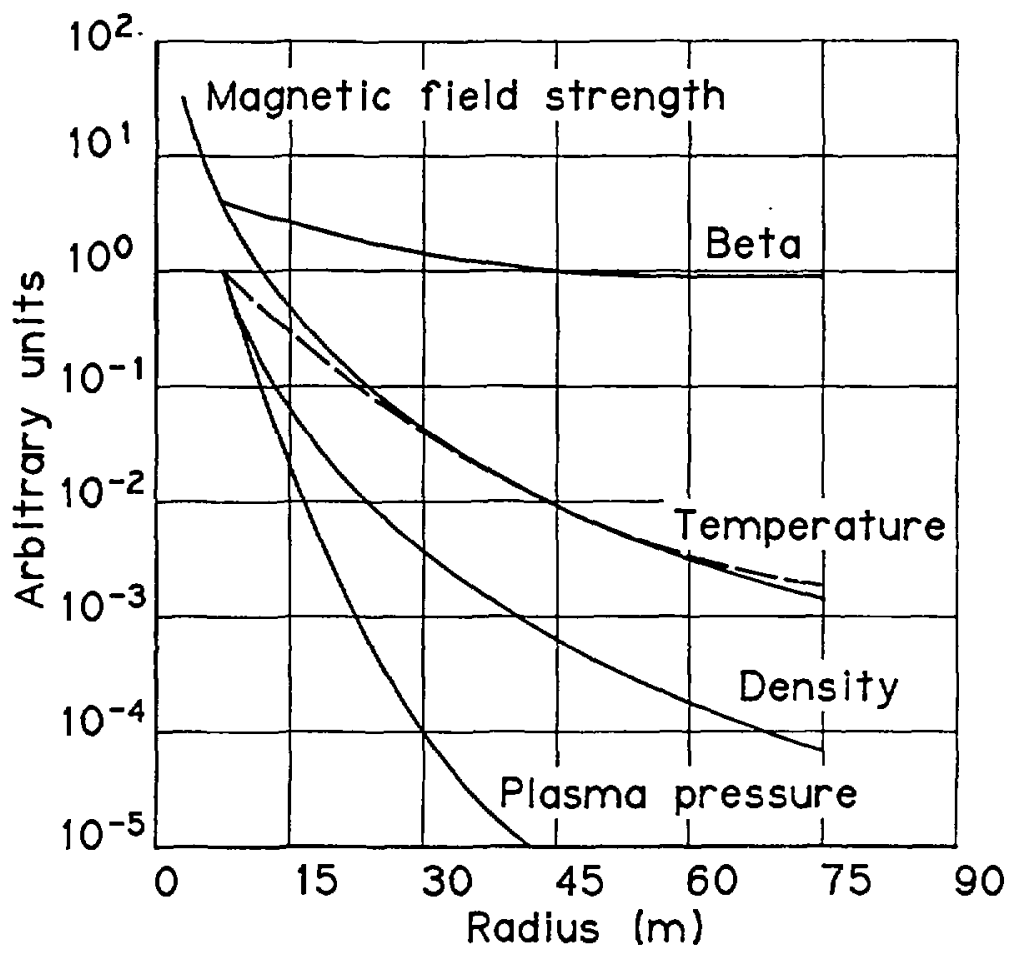

Figure 5. Approximate profiles of magnetic field, beta, temperature (dashed line), density, and plasma pressure (adapted from Ref. 5). 


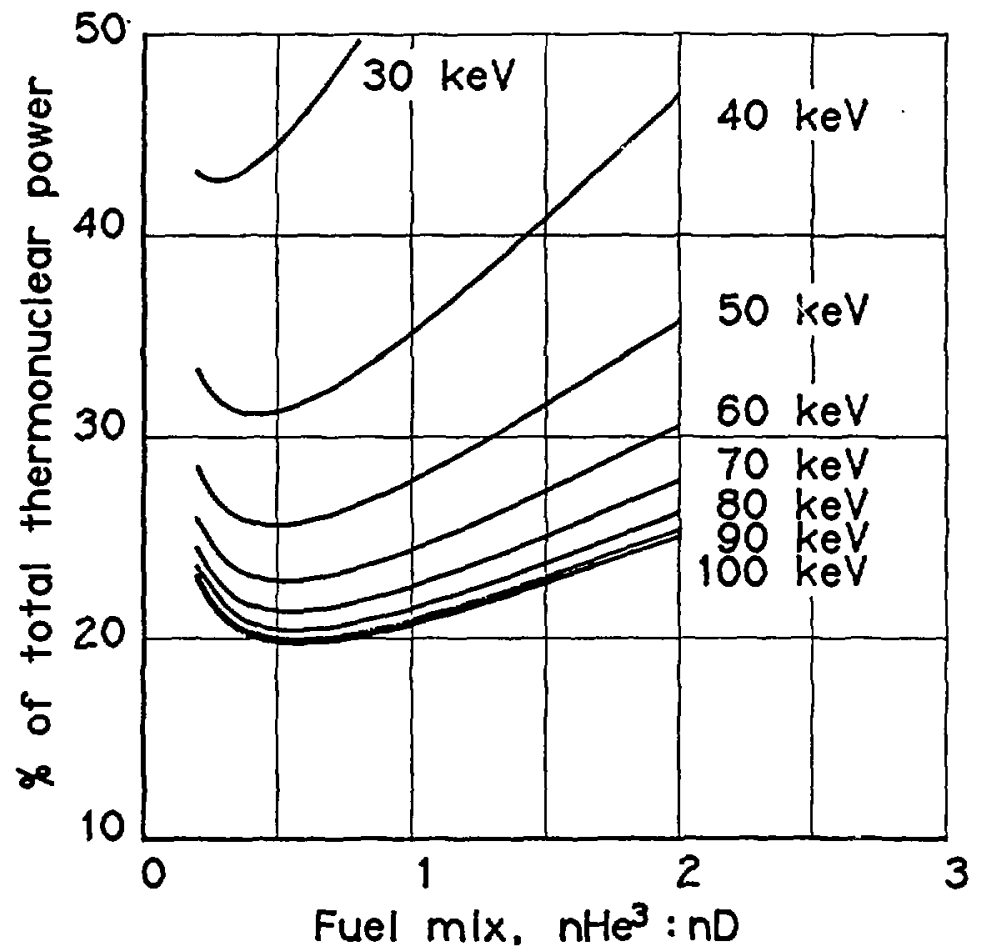

Figure 6. Power loss to the ring, as a percentage of the total thermonuclear power $P_{\text {fus }}$ for different temperatures as a function of the fuel mix $n_{\mathrm{Hd}} / n_{\mathrm{D}}$. (Courtesy S. A. Carpenter). 


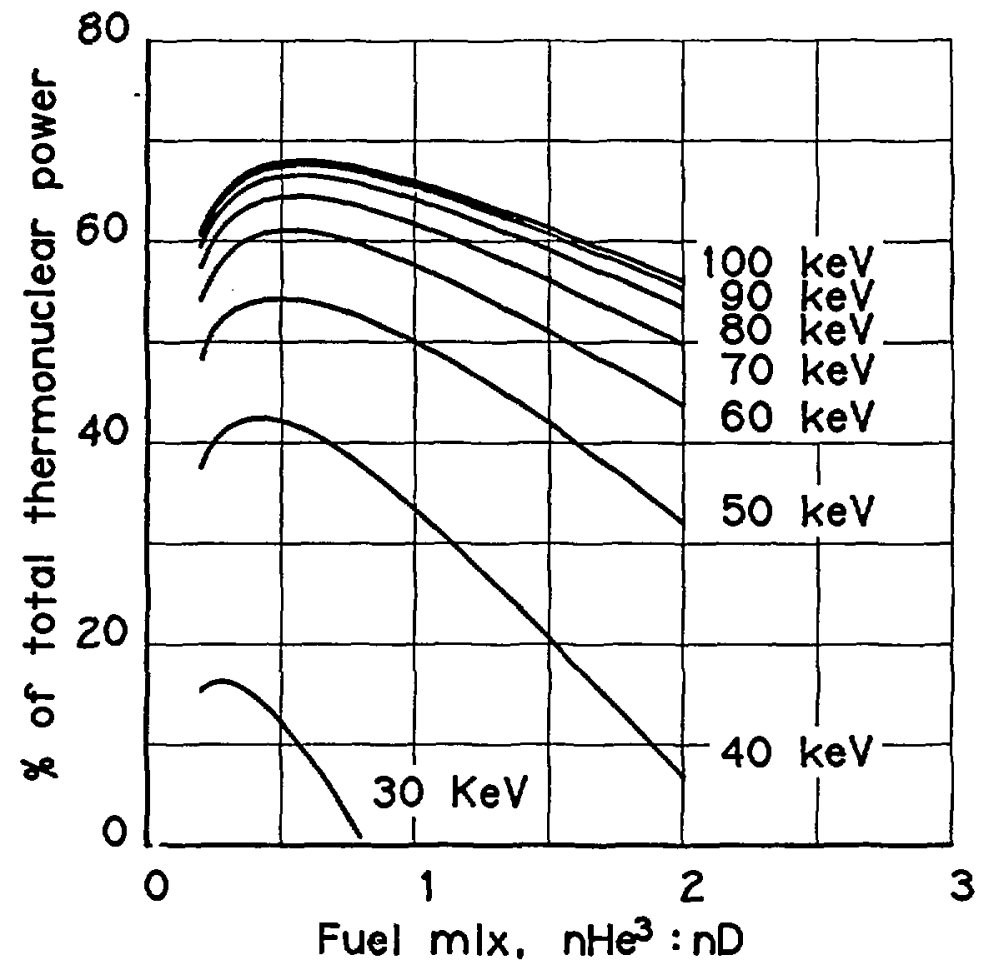

Figure 7. Power available for thrust, as a percentage of the total thermonuclear power $P_{\text {fus }}$ for different temperatures as a function of the fuel mix $n_{\mathrm{Hd}} / n_{\mathrm{D}}$. (Courtesy S. A. Carpenter). 


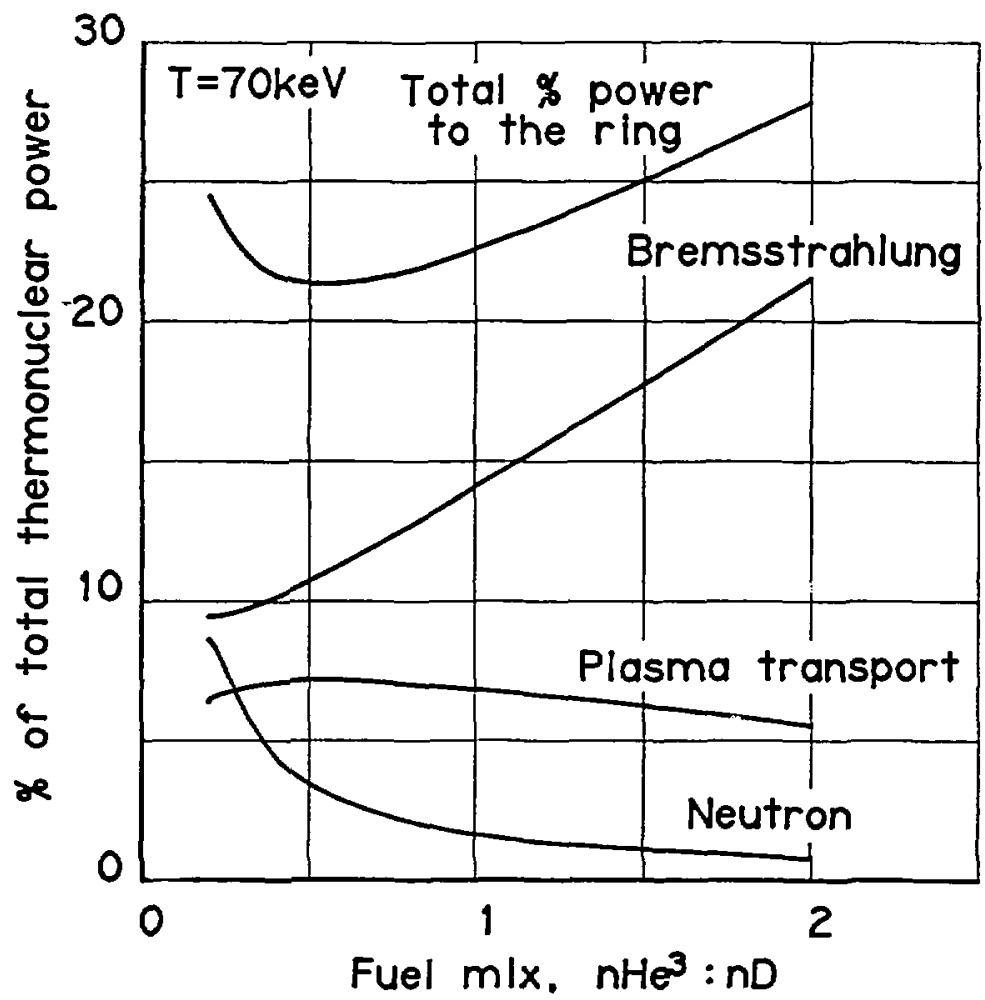

Figure 8. Various power losses to the sing, as a percentage of the total thermonuclear power $P_{\text {fus }}$ as $T=70 \mathrm{keV}$ as a function of the fuel mix $n_{\mathrm{Hd}} /{ }^{\prime} \mathrm{D}$. (Courtesy S. A. Carpenter). 


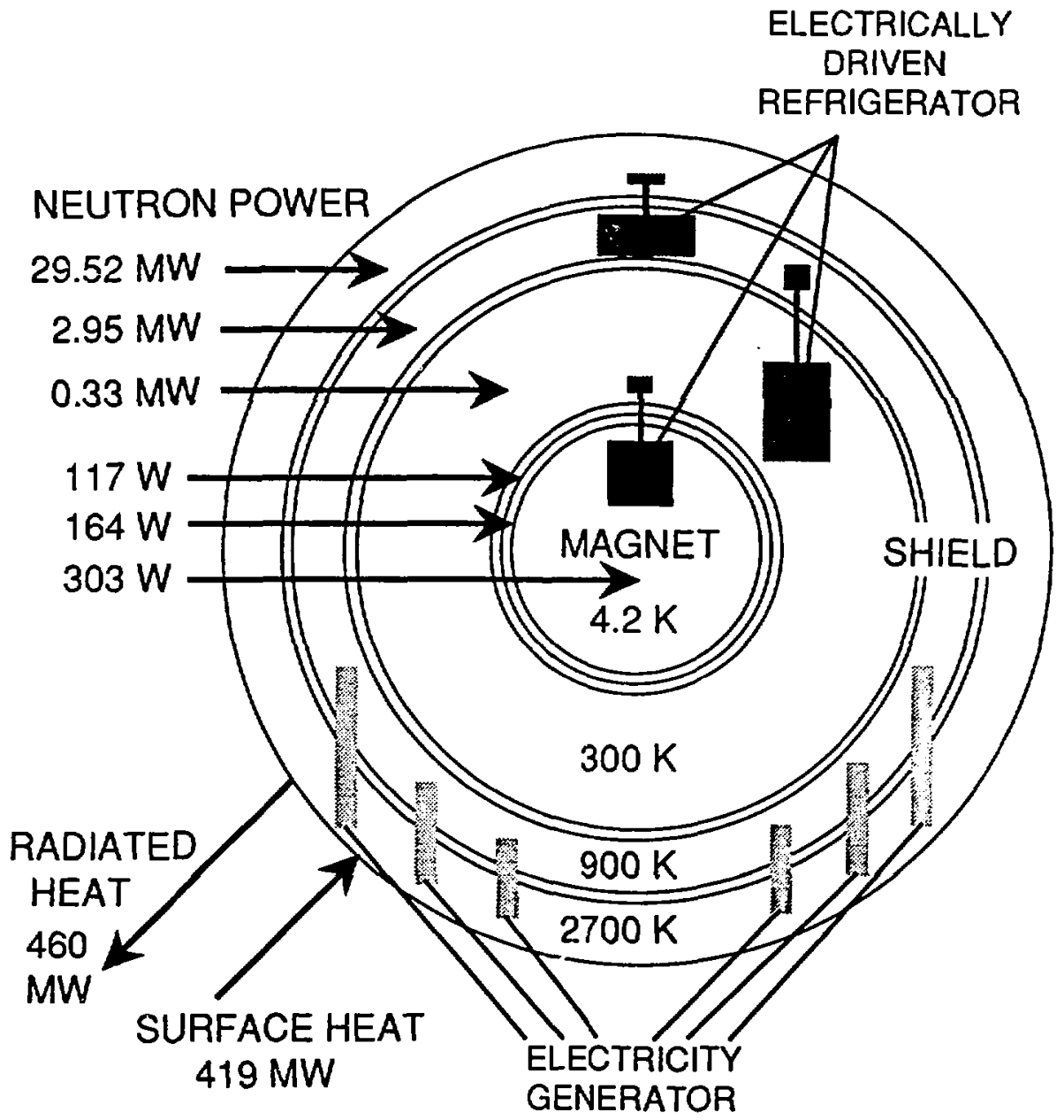

Figure 9. Ring design concept showing magnet, shield, and internal refrigeration scheme. 

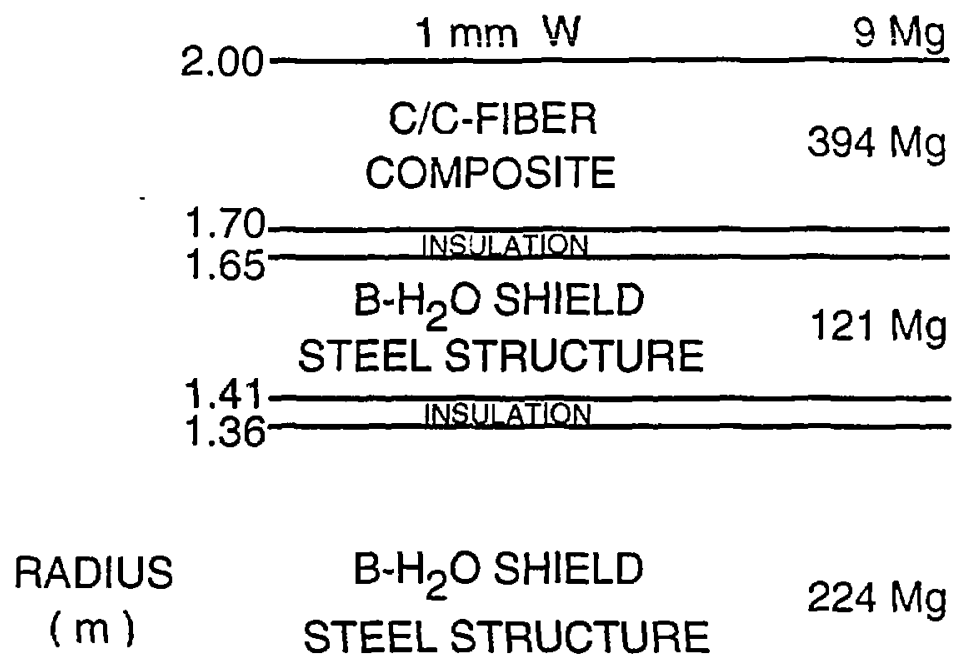

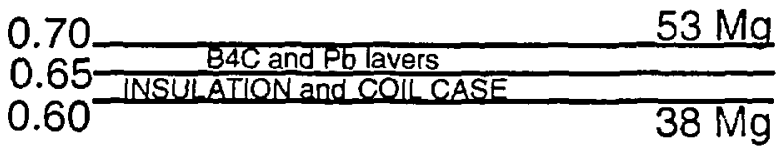

MAGNET $\quad 341 \mathrm{Mg}$

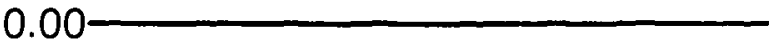

Figure 10. Radial build of magnet and shield, for Case B, Table I. First wall is at the top, axis at bottom. Masses are given for each layer at the right. 


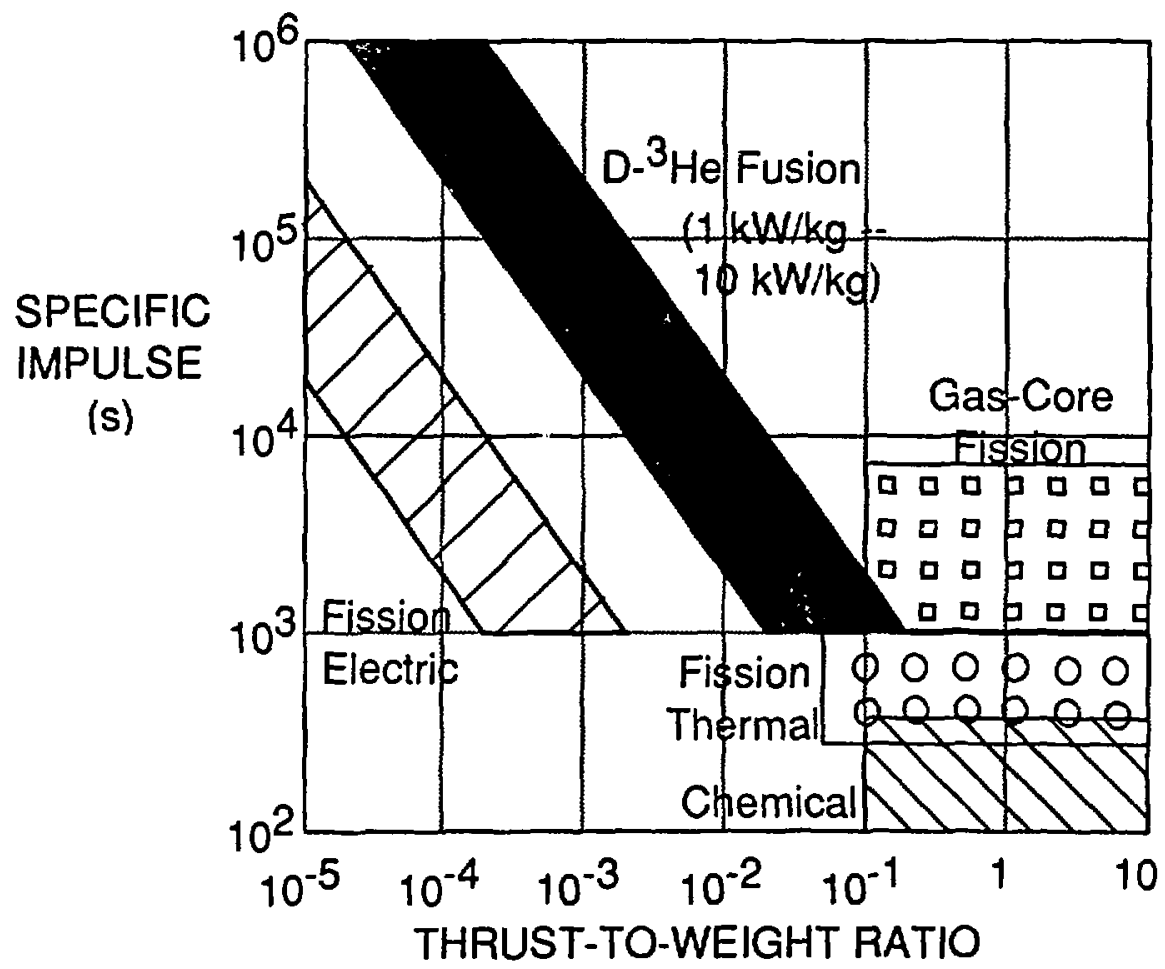

Figure 11. Comparison of $\mathrm{D}^{3} \mathrm{He}$ fusion with chemical, nuclear thermal, and nuclear electric propulsion systems. 


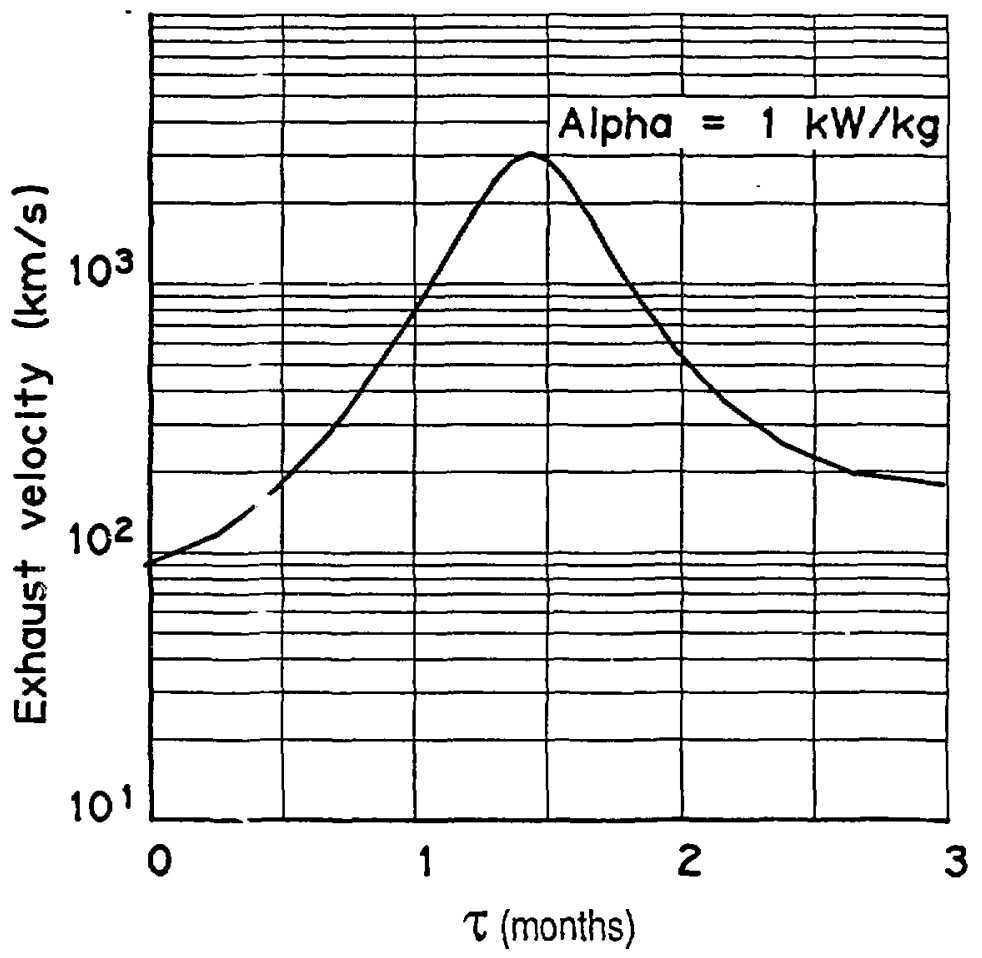

Figure 12. Exhaust velocity variation on a 3-month transfer trajectory to Mars (based on Stuh!:inger, Ref. 3). 


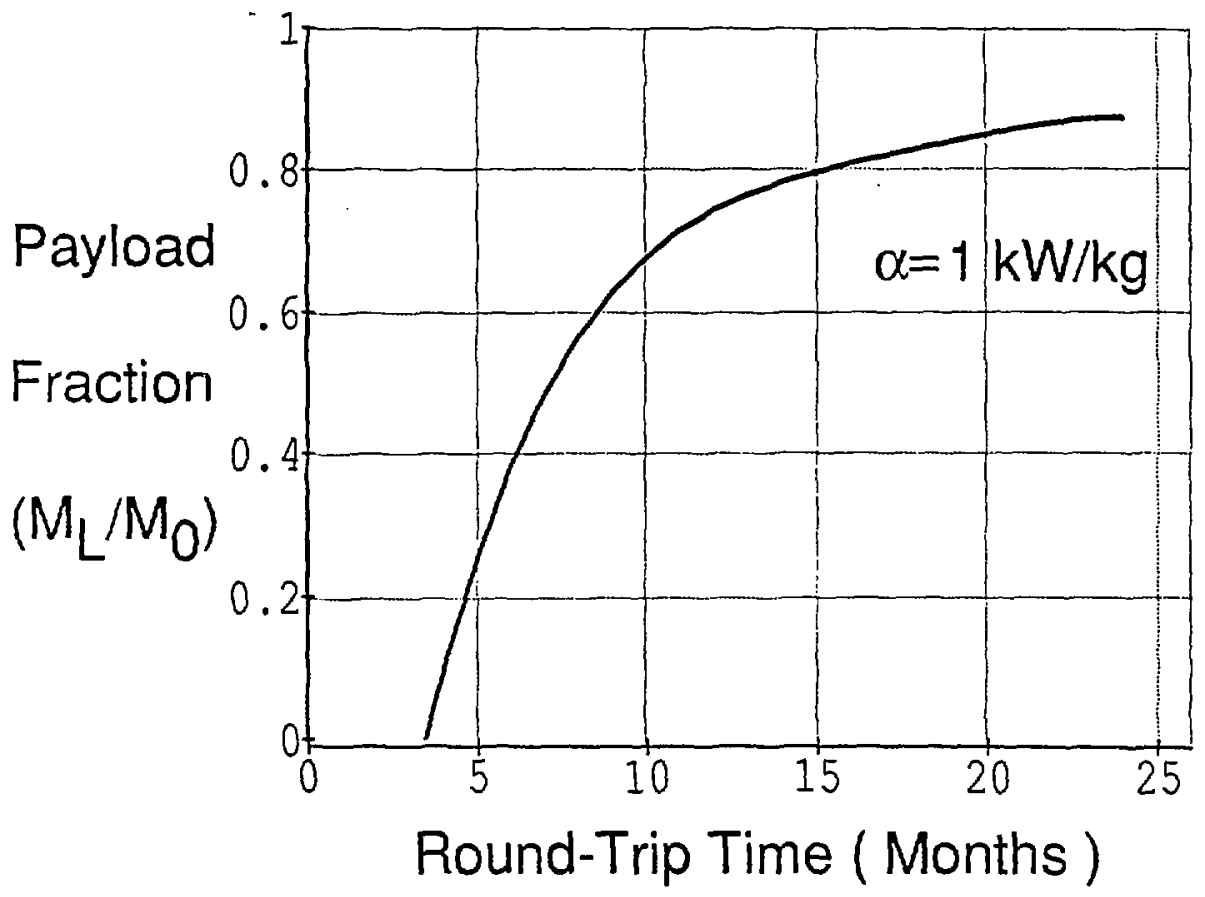

Figure 13. Earth-Mars payload fraction versus round-trip time. 


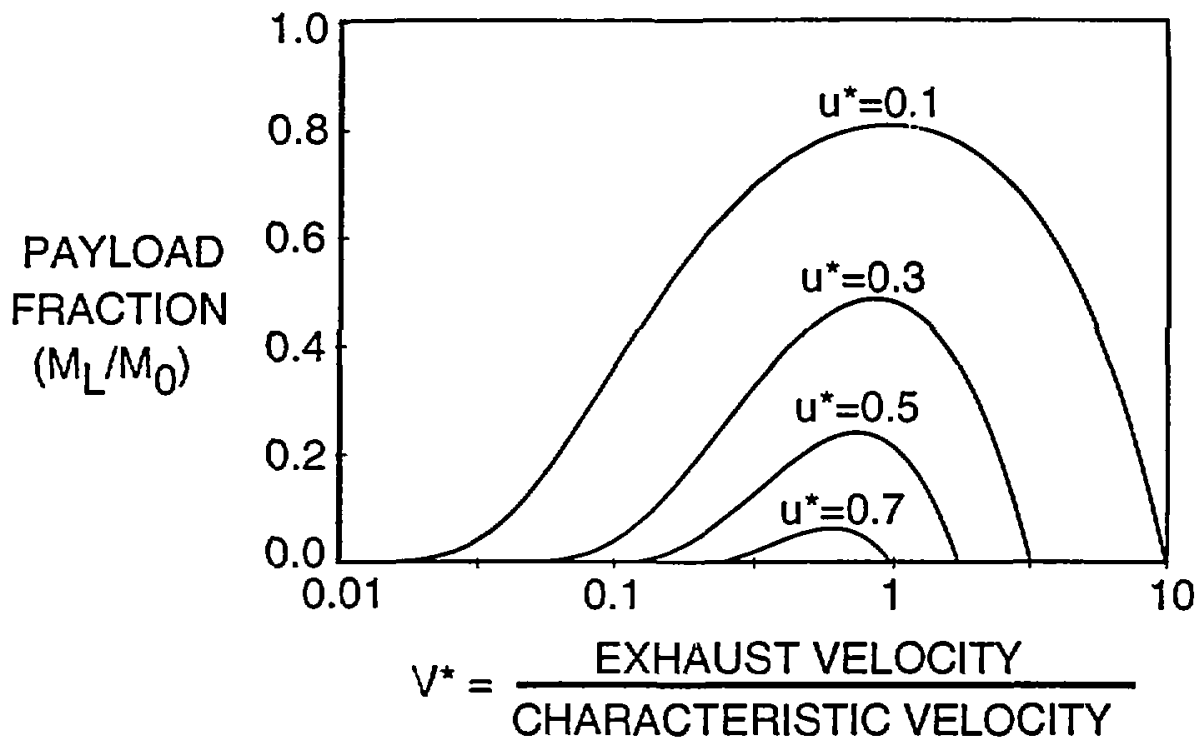

Figure 14 Payload fraction $M_{L} M_{0}$ versus exhaust velocity $v^{*}$ (normalized to the characteristic velocity $v_{c}$ ) for various values of the total velocity change $u^{*}$ (also normalized to $v_{c}$ ). 